Article

\title{
The Effect of $\beta$-Glycerophosphate Crosslinking on Chitosan Cytotoxicity and Properties of Hydrogels for Vaginal Application
}

\author{
Emilia Szymańska ${ }^{1, *}$, Katarzyna Sosnowska ${ }^{1}$, Wojciech Miltyk ${ }^{2}$, Małgorzata Rusak ${ }^{3}$, \\ Anna Basa ${ }^{4}$ and Katarzyna Winnicka ${ }^{1, *}$ \\ Received: 24 September 2015 ; Accepted: 28 October 2015 ; Published: 4 November 2015 \\ Academic Editor: Jianxun Ding \\ 1 Department of Pharmaceutical Technology, Medical University of Białystok, Mickiewicza 2c, \\ Białystok 15-222, Poland; katarzyna.sosnowska@umb.edu.pl \\ 2 Department of Pharmaceutical Analysis, Medical University of Białystok, Mickiewicza 2d, \\ Białystok 15-222, Poland; wmiltyk@umb.edu.pl \\ 3 Department of Haematological Diagnostics, Medical University of Białystok, Waszyngtona 15a, \\ Białystok 15-269, Poland; mrusak@umb.edu.pl \\ 4 Institute of Chemistry, University of Białystok, Hurtowa 1, Białystok 15-399, Poland; abasa@uwb.edu.pl \\ * Correspondence: esz@umb.edu.pl (E.S.); kwin@umb.edu.pl (K.W.); Tel./Fax: +48-857-485-616
}

\begin{abstract}
Mucoadhesive gelling systems based on chitosan and chitosan/ $\beta$-glycerophosphate $(\beta-G P)$ were developed in order to increase clotrimazole residence time in the vaginal cavity. $E x$ vivo mucoadhesiveness using porcine vaginal mucosa followed with mechanical, viscoelastic, and swelling properties of prepared hydrogels were evaluated. Drug-free, sterile, unmodified, and $\beta$-GP crosslinked chitosan were investigated for the in vitro cytotoxicity in CRL 2616 human vaginal mucosa cells using MTT assay, fluorescent microscopy, and flow cytometry analysis. Chitosan/ $\beta$-GP hydrogels exhibited pseudoplastic and thixotropic properties. Ionic interaction between $\beta-G P$ and chitosan improved mechanical properties of hydrogels in terms of hardness, cohesiveness, and compressibility. The hydrogels' ability to interact with porcine vaginal mucosa (measured as force of detachment and work of adhesion) was comparable to those obtained with reference mucoadhesive gel Replens ${ }^{\mathrm{TM}}$. Surprisingly, greater mucoadhesive properties were noticed for chitosan/ $\beta$-GP hydrogels. The cytotoxic effect of unmodified and $\beta$-GP crosslinked chitosan was hardly affected by chitosan molecular weight, exhibited mainly through inducing apoptosis, and was found to be significantly lower in the presence of chitosan/ $\beta$-GP. Furthermore, the higher amount of $\beta$-GP was used to crosslink chitosan, the lower cytotoxic effect was observed.
\end{abstract}

Keywords: chitosan; $\beta$-glycerophosphate; ion crosslinking; mucoadhesion; cytotoxicity; CRL 2616 cell line

\section{Introduction}

Vaginal route of administration offers a great number of advantages including the hepatic low systemic drug exposure, first pass-effect bypass, and improved bioavailability compared with the oral route $[1,2]$. Nevertheless, conventional vaginal dosage forms do not offer prolonged delivery of the drug. As a result of poor retention of drug carrier in the vaginal cavity, drug therapeutic efficacy is impaired. Feasible vaginal drug carriers should be characterized by the ease of application with minimal influence on body functions, capability of increased drug residence time after administration in the target site, and lack of toxicity. In the recent years, mucoadhesive delivery systems providing intimate contact between a dosage form and the vaginal mucosa have gained a great attention $[3,4]$. Among mucoadhesive polymers, chitosan (CS) is extensively studied in designing ocular [5], 
buccal [6], nasal [7], and vaginal dosage forms [8,9]. In addition, CS is currently receiving great interest in pharmaceutical and biomedical fields, particularly because of its penetration enhancement capability $[10,11]$ and antifungal activity [12-14]. Recently, plenty of data has drawn attention to the use of CS hydrogels in controlled drug delivery intended for vaginal administration $[15,16]$. Despite several advantages offered by CS hydrogels, including ease of administration, lubricating properties or acidic $\mathrm{pH}$ close to vaginal $\mathrm{pH}$ value $[17,18]$, hydrogels prepared with unmodified CS possess relatively low mechanical strength [19]. Modification of the CS structure by ion crosslinking enables the improvement of mechanical and rheological properties of its semisolid preparations [20]. Among various crosslinkers, $\beta$-glycerophosphate $(\beta-G P)$ allows the formation of homogeneous chitosan gel in mild conditions (without gel-like precipitate) with improved organoleptic properties [21]. It should be also pointed out that in combination with $\beta$-GP, CS becomes thermosensitive in diluted acids and can undergo gelation around body temperature [22]. These properties make CS/ $\beta$-GP material a promising tool for a variety of applications, such as local drug delivery systems or injectable carriers for tissue-engineering [23].

The aim of the study was to evaluate the influence of $\beta$-GP crosslinking on the physicochemical properties of CS hydrogels with regard to their usefulness as drug carriers for vaginal application. To characterize the hydrogels' in vitro swelling index, thermogelling behavior, mechanical and viscoelastic properties were investigated. In addition, particular effort was made to evaluate the mucoadhesive properties of CS and $\beta$-GP crosslinked CS hydrogels measured ex vivo using porcine vaginal mucosa. Clotrimazole (CLO)—an imidazole derivative safe and commonly used as the drug of choice for the mycotic infections of the genitourinary tract—was applied as a model agent [24].

Regarding the fact that any modification of CS backbone might alter the polymer cytotoxicity, the goal of this work was also to evaluate the cytotoxic effect of $\beta$-GP crosslinking by MTT assay followed by two independent methods of apoptosis measurement: flow cytometry and fluorescent microscopy assessment. To the best of our knowledge, there are no studies concerning cytotoxicity of $\beta$-GP crosslinked CS in vaginal cell cultures. The in vitro cytotoxicity profile of CS with different ratios of $\beta$-GP crosslinking using human vaginal mucosa epithelium CRL 2616 was reported for the first time.

\section{Experimental Section}

\subsection{Materials}

High quality low molecular weight $\left(\mathrm{L}_{\mathrm{Mw}} 80-200 \mathrm{kDa}\right.$; viscosity $32-38 \mathrm{mPa} \cdot \mathrm{s}$ at $25^{\circ} \mathrm{C}, 1 \%$ in $1 \%$ acetic acid) and medium molecular weight ( $\mathrm{M}_{\mathrm{Mw}} 200-400 \mathrm{kDa}$; viscosity $370-395 \mathrm{mPa} \cdot \mathrm{s}$ at $25^{\circ} \mathrm{C}, 1 \%$ in $1 \%$ acetic acid) chitosan with deacetylation degree $79.9 \%$ (determined by titration method [25]) was obtained from Heppe Medical Chitosan $\mathrm{GmbH}$ (Haale, Germany). Clotrimazole was a gift from Ziaja Ltd. (Gdańsk, Poland). Vaginal mucoadhesive gel Replens ${ }^{\mathrm{TM}}$ was purchased from APC Instytut Sp. z o.o. (Warsaw, Poland). $\beta$-glycerophosphate disodium salt hydrate, Cremophor $\mathrm{EL}$, dimethyl sulfoxide (DMSO, anhydrous), 3-(4,5-dimethylthiazol-2-yl)-2,5-diphenyltetrazolium bromide (MTT), acridine orange, and ethidium bromide were purchased from Sigma-Aldrich (Steinheim, Germany). Glycerolum $86 \%$, calcium chloride, acetic acid $80 \%$, sodium acetate, potassium dihydrogen phosphate, sodium hydroxide, and disodium hydrogen phosphate were obtained from Chempur (Piekary Ślaskie, Poland). D-Glucono-1, 5-lactone and sodium benzoate-natural preservative was from Lonza (Basel, Switzerland). Keratinocyte-Serum Free Medium (ker-SFM), human recombinant EGF, bovine pituitary extract, and Trypsin-EDTA were obtained from Life Technologies Sp. z o.o. (Warsaw, Poland). Apoptest-FITC was product of DakoCytomation (Glostrup, Denmark). Methanol was HPLC grade and it was purchased from Merck (Darmstadt, Germany). Water for HPLC was distilled and passed through a reverse osmosis system Milli-Q Reagent Water System (Billerica, MA, USA). 
Porcine vaginal mucosa from large white pigs weighting $\approx 200 \mathrm{~kg}$ was obtained from veterinary service of local slaughterhouse (Turośń Kościelna, Poland). Freshly excised tissue was washed and frozen at $-20^{\circ} \mathrm{C}$ immediately after an animal was sacrificed [26]. Samples were defrosted just before the experiment at ambient temperature and cut into $2.5 \mathrm{~cm}$ long and $2.0 \mathrm{~mm}$ thick pieces. Normal human vaginal epithelial cells (CRL 2616; VK2/E6E7) were purchased from American Type Culture Collection (Manassas, VA, USA).

\subsection{Preparation of Hydrogels}

Hydrogels were prepared using mechanical stirrer model DT 200 (Witko, Łódź, Poland) according to the method described previously [12]. Briefly, CS bases were obtained by dissolving proper amounts of CS in a gently heated acetic acid solution $(1.8 \%$ and $2.4 \% v / v$, respectively) and stirred until homogenous mixtures appeared. The weight ratio CS:acetic acid (0.6:1.0) was selected to achieve total dissolution of CS [27]. The initial pH of the CS base was around 4.0. Additionally, to prepare crosslinked CS hydrogels, $45 \%(w / w)$ aqueous solution of $\beta$-GP was prepared and chilled along with the CS base in the ice bath for $30 \mathrm{~min}$. The appropriate amount of cold $\beta$-GP solution necessary to adjust the $\mathrm{pH}$ of hydrogels to 4.5 was added dropwise to the cold CS base with continuous stirring. Thus, $100 \mathrm{~g}$ of hydrogel contained $1.89 \mathrm{~g}$ (F3) or $2.52 \mathrm{~g}$ (F4) of $\beta$-GP with a constant weight ratio chitosan to $\beta$-GP 1:0.63. The final polymer concentrations were $3 \%$ or $4 \%(w / w)$. Afterwards, glycerol was mixed with preservative in a mortar, and next suspension of CLO in Cremophor EL was carefully added. Finally, suitable amounts of unmodified CS or CS/ $\beta$-GP base was mixed carefully with those excipients to obtain uniform dispersion of CLO in the hydrogel structure.

\section{3. $p H$ Determination}

The $\mathrm{pH}$ of initial CS bases and the final hydrogels' formulations were measured in triplicate by a glass electrode of the $\mathrm{pH}$-meter Orion 3 Star (ThermoScientific, Waltham, MA, USA) after the day of preparation.

\subsection{Particles Size Analysis}

Hydrogels were observed using optical microscope Motic BA 400 (Moticon, Wetzlar, Germany) using total magnification $40 \times$ and $100 \times$. Briefly, $0.5 \mathrm{mg}$ of each hydrogel (corresponding to $10 \mu \mathrm{g}$ of CLO) was placed on a glass slide and the longest dimension from edge to edge of a particle was measured for particles present in at least three different areas of observation [28].

\subsection{Drug Content}

CLO content was evaluated after the extraction of hydrogel samples using absolute ethanol, centrifugation at $4000 \mathrm{rpm}$ for $20 \mathrm{~min}$, and filtration through $0.45 \mu \mathrm{m}$ syringe nylon filters. One milliliter samples were then suitably diluted with mobile phase and analysed for CLO content by HPLC method according to [8] in the following conditions: Zorbax Eclipse XDB-C18, $4.6 \mathrm{~mm} \times 150 \mathrm{~mm}, 5 \mu \mathrm{m}$ column (Agilent, Waldbronn, Germany); mobile phase: methanol-phosphate buffer $\mathrm{pH} 7.4(4: 1, v / v)$, flow rate: $1.0 \mathrm{~mL} \cdot \mathrm{min}^{-1}$; UV detection at $210 \mathrm{~nm}$; retention time $5.3 \mathrm{~min}$; the standard calibration curve was linear over the range of $1-100 \mu \mathrm{g} \cdot \mathrm{mL}^{-1}\left(R^{2}=0.997\right)$.

\subsection{Determination of Gelation Time}

Gelation time was measured by immersing the test tubes containing CS/ $\beta$-GP hydrogels in a thermostated water bath at $37^{\circ} \mathrm{C}[22,29]$. In order to investigate whether the formulations underwent gelation, the vials were inverted horizontally at predetermined time intervals over $4 \mathrm{~h}$, and the gelation time was defined as the time at which the samples no longer flow. 


\subsection{Morphology of the Hydrogels}

Scanning electron microscopy (SEM) analysis was performed to evaluate the hydrogels' morphology. Prior to analysis, samples were poured into Petri dishes, stored at $-80{ }^{\circ} \mathrm{C}$ for three days and dehydrated using lyophilization (Centrivap Concentrator FreeZone6, Labconco, Kansas city, MO, USA) according to [30] with modifications. Next, the samples were sputter-coated with gold $(6.5 \mathrm{~nm})$ in an argon atmosphere (Leica EM AC 2000, Wetzlar, Germany) and imaged using SEM Hitachi SH 200 (Tokyo, Japan).

\subsection{Viscosity Measurement}

The rheological behavior of the hydrogels was measured using a digital rotational Brookfield RVDV-III ULTRA Viscometer (Brookfield Engineering Laboratories, Middlebro, MA, USA). All measurements of apparent viscosity were carried out at $25^{\circ} \mathrm{C}$ and $37{ }^{\circ} \mathrm{C}$. Hydrogels $(0.5 \mathrm{~g})$ were placed in the thermostated sampler holder of the viscometer, allowed to equilibrate for $10 \mathrm{~min}$ at $25 \pm 0.5^{\circ} \mathrm{C}$ or $37 \pm 0.5^{\circ} \mathrm{C}$, and then $\mathrm{C}-52$ spindle (with the shear rate range from 2 to $12 \mathrm{~s}^{-1}$ ) was lowered into the sample. The shearing time was $30 \mathrm{~s}$. Each experiment was carried out three times.

\subsection{Mechanical Properties}

The mechanical properties of the hydrogels were carried out using TA.XT.Plus Texture Analyser (Stable MicroSystem, Godalming, UK) equipped with a $5 \mathrm{~kg}$ load cell and backward extrusion measuring system. A disc ( $25 \mathrm{~mm}$ diameter) was compressed with a speed of $2 \mathrm{~mm} \cdot \mathrm{s}^{-1}$ into each formulation $(30 \mathrm{~g})$ to a defined depth $(5 \mathrm{~mm})$ for a period of 5-10 $\mathrm{s}$. The parameters were determined during preliminary experiments (data not shown). As a result, a force-time curve was obtained, the mechanical parameters, namely hardness, compressibility, adhesiveness, cohesiveness and elasticity were calculated using Texture Exponent 32 software [31]. Experiments were carried out in triplicate.

\subsection{Swelling Index Study}

Lyophilized hydrogel samples were weighted and placed separately in a $25 \mathrm{~mL}$ beaker containing $10 \mathrm{~mL}$ acetic buffer ( $\mathrm{pH}$ 4.5) (with the following composition (per liter of distilled water): anhydrous sodium acetate $63 \mathrm{~g}$ and acetic acid $90 \mathrm{~mL}$; ionic strength: $0.14 \mathrm{M}$ acetic acid/0.08 M sodium acetate). The beakers were stored at $37 \pm 0.5{ }^{\circ} \mathrm{C}$. At the predetermined time intervals $(0.25,0.5,0.75,1,2,3,4$ and $5 \mathrm{~h})$ samples were removed, wiped off with filter paper, and reweighted. The swelling index was calculated by using the following formula:

$$
S I=\frac{W_{2}-W_{1}}{W_{1}}
$$

where SI is the swelling index, $W_{1}$ is the initial weight of the hydrogel, $W_{2}$ is the weight of the hydrogel after the particular swelling time interval. Each experiment was performed in triplicate.

\subsection{Determination of the in Vitro Mucoadhesive Properties}

A TA.XT.Plus Texture Analyser (Stable Microsystems, Godalming, UK) equipped with a cylinder probe and the measuring system A/GMP for semisolid dosage forms was used for mucoadhesion test. The in vitro mucoadhesive properties of hydrogels were assessed on porcine vaginal mucosa (moisturized with $100 \mu \mathrm{L}$ of physiological solution), which was adhered by double-sided tape to the platform below the texture analyzer probe. The tests were conducted at $37 \pm 0.5^{\circ} \mathrm{C}$. An acquisition rate of 200 points. $\mathrm{s}^{-1}$ and a trigger force of $0.003 \mathrm{~N}$ were selected to all measurements. Hydrogel $(1.5 \mathrm{~mL})$ was set on the upper probe and secured with the attached support collar to maintain the sample whilst it was setting. Before testing, the support collar was removed to completely expose the hydrogel surface. Next, the probe lowered onto the surface of the porcine vaginal mucosa with a constant speed of $0.5 \mathrm{~mm} \cdot \mathrm{s}^{-1}$. After keeping a contact time for $180 \mathrm{~s}$ under an initial contact force 
$(0.5 \mathrm{~N})$, the parameters of which were determined during preliminary experiments (data not shown), the two surfaces were separated at a constant rate of $0.1 \mathrm{~mm} \cdot \mathrm{s}^{-1}$. The maximum detachment force $\left(F_{\max }\right)$ as a function of displacement was recorded directly from Texture Exponent 32 software and the work of mucoadhesion $\left(W_{\mathrm{ad}}\right)$ expressed in $\mu \mathrm{J}$ was calculated from the area under the force versus distance curve [8]. Commercially available mucoadhesive gel Replens ${ }^{\mathrm{TM}}$ was used as a control. Each experiment was carried out at least six times.

\subsection{Stability Data}

The organoleptic properties (color, odor), $\mathrm{pH}$, drug particle's diameter, drug content uniformity, and viscosity of all formulations stored at $4 \pm 2{ }^{\circ} \mathrm{C}$ were examined on days $0,7,14,21$ and 28 . At predetermined time intervals, formulations were maintained for $3 \mathrm{~h}$ at ambient temperature prior to analysis.

\section{In Vitro Release of CLO}

In vitro release of CLO from freshly prepared hydrogels and upon 4-week storage was evaluated according to previously described method [12] through natural cellulose membrane (Cuprophan, Medicell, London, UK) using an Enhancer cell (Agilent Technologies, Cary, NC, USA) with an effective diffusion area of $3.80 \mathrm{~cm}^{2}$. About $2.0 \mathrm{~g}$ of each hydrogel was placed in the drug reservoir on the top of the membrane, making certain that no entrapped air was present at the interface of semisolid dosage form and the membrane. A USP dissolution Apparatus II (Agilent 708-DS, Agilent Technologies, Cary, NC, USA) equipped with mini vessels $(250 \mathrm{~mL})$ and mini paddles was applied to measure the release of CLO from the enhancer cell assembly. The dissolution medium was acetic buffer $\mathrm{pH} 4.5(100 \mathrm{~mL})$ with addition of $1 \%$ surfactant maintained at $37 \pm 0.5^{\circ} \mathrm{C}$ and stirred at $75 \mathrm{rpm}$. Samples (2 mL) were withdrawn at the predetermined time intervals $(0.5,1,2,3,4,5,6,8,24,48 \mathrm{~h})$, filtered through $0.45 \mu \mathrm{m}$ CA paper filters, diluted with mobile phase, and analyzed using the HPLC method (as described in Section 2.5.). Withdrawn samples were replaced with equal volumes of the fresh medium. Sink conditions were maintained throughout the experiment. All release experiments were conducted in triplicate.

\subsection{Cell Culture}

CRL 2616 human vaginal mucosa cell line was maintained according to the attached protocol in ker-SFM with $0.1 \mathrm{ng} \cdot \mathrm{mL}^{-1}$ human recombinant EGF, $0.05 \mathrm{mg} \cdot \mathrm{mL}^{-1}$ bovine pituitary extract, and additional $44.1 \mathrm{mg} \cdot \mathrm{L}^{-1}$ calcium chloride (final concentration $0.4 \mathrm{mM}$ ). Cells were cultured in Costar flasks and grown at $37{ }^{\circ} \mathrm{C}$ and in a $5 \% \mathrm{CO}_{2}$ atmosphere to achieve subconfluence of $70 \%-80 \%$. After discarding culture medium, sub-confluent cells were rinsed with $0.25 \%(w / v)$ Trypsin- $0.03 \%(w / v)$ EDTA solution, counted in hemocytometer and seeded in six-well plates (Nunc) in $2 \mathrm{~mL}$ ker-SFM. Cultures were re-fed with $2 \mathrm{~mL}$ media per well every two to three days. The cells that reached about $70 \%-80 \%$ of confluency were used for the assays.

\subsection{Preparation of CS Solutions for Cytotoxicity Studies}

Sterile drug-free CS formulations for the in vitro cytotoxicity studies were prepared under aseptic conditions in a laminar flow cabinet Lamil Plus 13 equipped with HEPA filters (Karstulan Metalli Oy, Karstula, Finland). Chitosan with $\mathrm{L}_{\mathrm{Mw}}$ and $\beta$-GP solutions were sterilized using $0.22 \mu \mathrm{m}$ PTFE membrane syringe filters (Millipore, Billerica, MA, USA). To prepare high purity level $\mathrm{M}_{\mathrm{Mw}} \mathrm{CS}$ samples, CS powder was sterilized by ultraviolet light radiation $(\lambda 254 \mathrm{~nm}, 30 \mathrm{~min})$ prior dilution in solvent autoclaved at $121^{\circ} \mathrm{C}, 1014 \mathrm{kBa}$ for $20 \mathrm{~min}$ (SterilClave 24BHD, Amadar, Poland). The composition of sterile CS formulations for the in vitro cytotoxicity tests is given in Section 3.5. In Vitro Cytotoxicity Evaluation. 


\subsection{MTT Assay}

The cytotoxicity test was performed according to the method of Carmichael [32] with modifications using 3-(4,5-dimethylthiazol-2-yl)-2,5-diphenyltetrazolium bromide (MTT). Unmodified CS, CS/1GP, and CS/hGP at different concentrations were diluted in cell culture medium at $37^{\circ} \mathrm{C}$ for $1 \mathrm{~h}$. The $\mathrm{pH}$ of the medium with samples varied in the range between 6.72 (for unmodified CS) to 7.55 (for CS/hGP formulations). Afterwards, there were added to a six-well plates containing $4 \times 10^{5}$ per well CRL 2616 confluent cells and incubated for $4 \mathrm{~h}$ at $37{ }^{\circ} \mathrm{C}$ in a $5 \% \mathrm{CO}_{2}$ humidified atmosphere. Then the culture medium was discarded, cells were rinsed three times with phosphate buffered saline (PBS) and then incubated for $4 \mathrm{~h}$ in $1 \mathrm{~mL}$ of MTT solution $\left(0.5 \mathrm{mg} \cdot \mathrm{mL}^{-1}\right.$ of PBS) at $37^{\circ} \mathrm{C}$. Medium was removed from the wells, and the cells were lyzed in $200 \mu \mathrm{L}$ of DMSO with $20 \mu \mathrm{L}$ of Sorensen's buffer $\left(0.1 \mathrm{~mol} \cdot \mathrm{L}^{-1}\right.$ glycine with $\left.0.1 \mathrm{~mol} \cdot \mathrm{L}^{-1} \mathrm{NaCl}, \mathrm{pH} 10.5\right)$. The absorbance of converted dye in living cells was measured at a wavelength of $570 \mathrm{~nm}$. Cell viability of CRL 2616 cells cultured in the presence of studied compounds was calculated as a percent of control cells. The control comprising cells not exposed to the chitosan material. After treatment of the cells with the polymer, the ratio of survived to dead cells in tested and control cells was calculated for each unmodified or $\mathrm{CS} / \beta-\mathrm{GP}$ concentration. Experiments were performed for at least six independent replicates.

\subsection{Flow Cytometry Assessment of Annexin V Binding}

Apoptosis was determined by assessment of phosphatidylserine exposure by Annexin V-FITC binding using the Annexin V-FITC staining kit (Apoptest-FITC) according to the manufacturer's instruction, followed by flow cytometry analysis (Becton Dickinson FACS Calibur, BD Biosciences, San Jose, CA, USA). Briefly, after treatment for $4 \mathrm{~h}$ with the analyzed compounds, the cells were collected, washed twice with cold PBS and resuspended in $100 \mu \mathrm{L}$ binding buffer. Next, $2 \mu \mathrm{L}$ Annexin V-FITC and $5 \mu \mathrm{L}$ propidium iodide were added and incubated for $15 \mathrm{~min}$ in dark at $25^{\circ} \mathrm{C}$. Experiments were performed at least in triplicate.

\subsection{Fluorescent Microscopy Assay}

To analyze apoptosis, cell viability was estimated $4 \mathrm{~h}$ after the addition of various concentrations of unmodified CS, lGP, and hGP crosslinked CS. The cell suspension $(250 \mu \mathrm{L})$ was stained with $10 \mu \mathrm{L}$ of the dye mixture (10 $\mu \mathrm{M}$ acridine orange and $10 \mu \mathrm{M}$ ethidium bromide), which was prepared in PBS. Two hundred cells per sample were examined by fluorescence microscopy (Olympus CH30, Olympus Opticon Inc., Tokyo, Japan), according to the following criteria: viable cells with normal nuclei (fine reticular pattern of green stain in the nucleus and red/orange granules in the cytoplasm); viable cells with apoptotic nuclei (green chromatin which is highly condensed or fragmented and uniformly stained by the acridine orange); nonviable cells with normal nuclei (bright orange chromatin with organized structure); and nonviable cells with apoptotic nuclei (bright orange chromatin which is highly condensed or fragmented). The control samples were cells incubated without analyzed compounds. Experiments were performed at least in triplicate. The representative images were captured using a Nikon Eclipse E800 digital camera (Nikon, Tokyo, Japan) at a total of $1000 \times$ magnification.

\subsection{Statistical Analysis}

Quantitative variables were expressed as the mean \pm standard deviation and/or the median. A statistical analysis was performed using nonparametric techniques: the Kruskal-Wallis and Mann-Whitney $U$ test with the Statistica 10.0 software. Differences between groups were considered to be significant at $p<0.05$. 


\section{Results and Discussion}

\subsection{Characterization of Hydrogels}

In order to prolong drug residence time at the site of infection and improve drug therapeutic efficacy in the vaginal cavity, mucoadhesive hydrogels have recently gained great attention as vaginal delivery systems. The goal of this work was to assess the influence of $\beta$-GP crosslinking on the physicochemical properties of CS hydrogels for vaginal application of CLO. Previously data published by our group proved that designed formulations with unmodified and $\beta$-GP crosslinked CS appear to be promising vaginal delivery systems for CLO as they were found to enhance its anti-Candida activity and display prolonged drug release profile [12]. Hydrogels' composition is presented in Table 1.

Table 1. Composition of hydrogels with unmodified or $\beta$-GP crosslinked chitosan (CS).

\begin{tabular}{ccccc}
\hline \multirow{2}{*}{ Component (g) } & \multicolumn{5}{c}{ Formulation } \\
\cline { 2 - 5 } & \multicolumn{2}{c}{ Unmodified chitosan } & \multicolumn{2}{c}{ Ion crosslinked chitosan } \\
\cline { 2 - 5 } & F1 & F2 & F3 & F4 \\
\hline CLO & 2.0 & 2.0 & 2.0 & 2.0 \\
\hline CS & 3.0 & 4.0 & 3.0 & 4.0 \\
\hline Glycerolum 86\% & 5.0 & 5.0 & 5.0 & 5.0 \\
\hline Cremophor EL & 6.0 & 6.0 & 6.0 & $5.59^{* *}$ \\
\hline$\beta-G P 45 \%(w / w)$ & - & - & $4.2^{* *}$ & 1.0 \\
\hline $\begin{array}{c}\text { D-Glucono-1,5-lactone and } \\
\text { sodium benzoate }\end{array}$ & 1.0 & 1.0 & 1.0 & - \\
\hline $1.8 \%$ Acetic acid ad & 100.0 & - & 100.0 & 100.0 \\
\hline $2.4 \%$ Acetic acid ad & - & 100.0 & - & \\
\hline
\end{tabular}

* Designed to be administered in a dosage $100 \mathrm{mg}$ per $5 \mathrm{~g}$ of hydrogel; ${ }^{* *}$ The amount of $\beta$-GP (corresponds with CS concentration) necessary to simulate vaginal $\mathrm{pH} 4.5$.

In order to prevent precipitation of the suspended drug particles, two concentrations ( $3 \%$ and $4 \%)$ of CS with medium molecular weight $\left(\mathrm{M}_{\mathrm{Mw}} 200-400 \mathrm{kDa}\right)$ were employed. The concentration of $\beta-G P-a n$ ion crosslinker with the mild alkalinity $\left(\mathrm{p} K_{\mathrm{a}}=6.34\right)$ applied in formulation $\mathrm{F} 3$ and F4-was carefully selected in order to simulate vaginal $\mathrm{pH}$ value of the CS hydrogels and to improve hydrogels' mechanical properties. As it is presented in Table 2, particle size, $\mathrm{pH}$, drug content and gelation time of hydrogels with unmodified and $\beta$-GP crosslinked CS were estimated.

Table 2. Physicochemical parameters of prepared hydrogels with unmodified or $\beta$-GP crosslinked CS. nt.-not tested.

\begin{tabular}{|c|c|c|c|c|}
\hline \multirow{3}{*}{ Parameter } & \multicolumn{4}{|c|}{ Formulation } \\
\hline & \multicolumn{2}{|c|}{ Unmodified chitosan } & \multicolumn{2}{|c|}{ Ion crosslinked chitosan } \\
\hline & F1 & F2 & F3 & $\mathbf{F 4}$ \\
\hline $\mathrm{pH}$ & $4.06 \pm 0.02$ & $4.08 \pm 0.01$ & $4.54 \pm 0.04$ & $4.56 \pm 0.03$ \\
\hline Drug particles size $(\mu \mathrm{m})$ & $5.9-49.5$ & $5.8-47.2$ & $4.1-39.9$ & $3.8-41.5$ \\
\hline$($ mean \pm S.D. $)$ & $(26.8 \pm 22.1)$ & $(27.5 \pm 20.4)$ & $(22.9 \pm 17.0)$ & $(24.1 \pm 16.4)$ \\
\hline Gelation time at $37^{\circ} \mathrm{C}(\mathrm{min})$ & nt. & nt. & 197 & 228 \\
\hline Drug content $(\%)$ & $95.6 \pm 4.9$ & $98.2 \pm 3.5$ & $97.3 \pm 4.1$ & $97.4 \pm 3.3$ \\
\hline
\end{tabular}

Prepared hydrogels possessed smooth, uniform consistency. The presence of suspended CLO gave the formulations an off-white color. Drug particles were found to have irregular, equant shape with average particles size below $50 \mu \mathrm{m}$ in all investigated formulations (Figure 1A,B). 


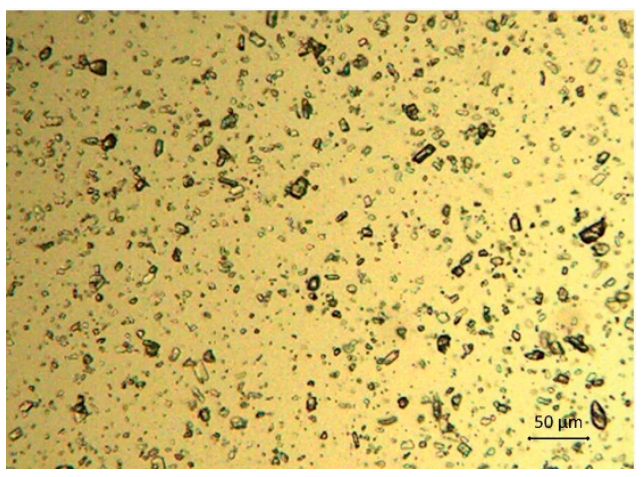

(A)

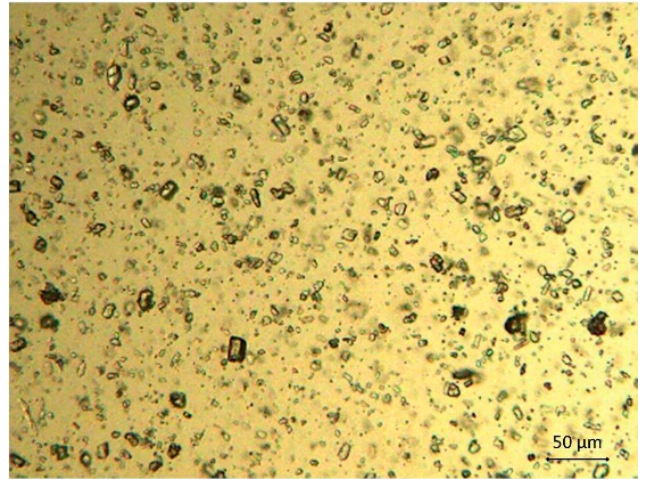

(B)

Figure 1. The optical images of F1 (A) and F3 hydrogels (B) (original magnification $100 \times$ ).

All hydrogels displayed the $\mathrm{pH}$ values $\leqslant 4.6$, which was maintained within the physiological values 3.5 to 4.9 [1] and should assure efficient drug permeation without causing vaginal irritation. The slight increase of $\mathrm{pH}$ with the increase of chitosan concentration was probably because of the decrease in the number of hydrogen ions used for protonation of the free amino groups [33]. The particle size of suspended CLO ranged from 3.8 to $49.5 \mu \mathrm{m}$ and was found to slightly decrease in the presence of ion crosslinker. The drug content was found to be uniform and was within acceptable USP limit $90 \%-110 \%$ in all investigated formulations [34].

Scanning electron microscopy (SEM) analysis was performed to evaluate the influence of $\beta$-GP on the internal CS hydrogel morphology. Representative SEM images are shown in Figure 2. It was noticed that hydrogels with unmodified CS (Figure 2A) possessed a diversified, porous structure with a high degree of interconnectivity and irregular pore shape, whereas CS/ $\beta$-GP hydrogels (Figure 2B) presented more compact and homogenous structure.
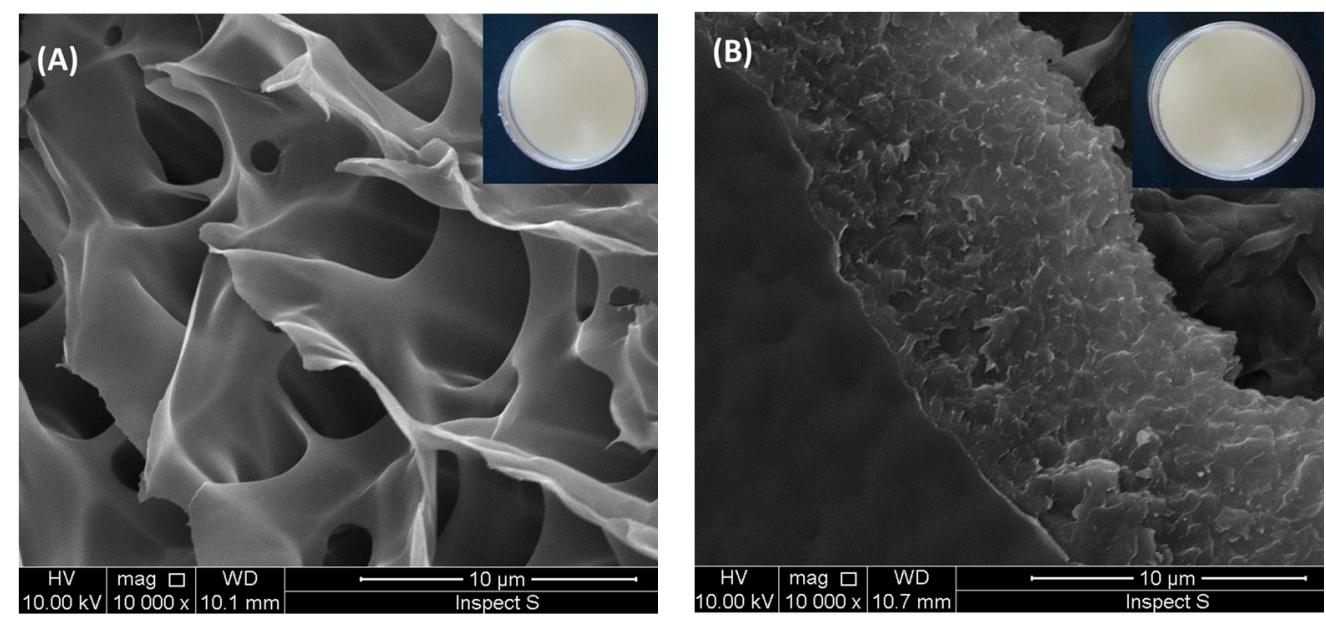

Figure 2. Scanning electron microscopy (SEM) images presenting cross-section microstructure of F1 (A) and F3 hydrogels (B) (original magnification 10,000×). Images of hydrogel F1 and F3 were shown insert.

CS hydrogels crosslinked with $\beta$-GP were found to exhibit some thermosensitive properties although their gelation time was prolonged and sol-gel transition took place within $4 \mathrm{~h}$. The time and temperature of chitosan gelling depends on the several factors, including polymers' deacetylation degree, preparation procedure, and the amount of crosslinking agent [4]. The obtained results are in the agreement with Chenite $e t$ al., who noticed that $\mathrm{pH}$ of CS/ $\beta$-GP solution (which corresponds 
to the amount of $\beta$-GP added) influences the gelation mechanism and formulations with $\mathrm{pH}<7.2$ represented higher values of gelation temperature and time [35]. Formulation F3 presented slightly shorter gelation time compared with hydrogel F4 probably as a consequence of lower polymer concentration $[22,36]$.

\subsection{Viscosity and Mechanical Measurements}

Rheological characterization of vaginal semisolid dosage forms provides the specific information about application, spreadability behavior, and patient acceptability. Since the rheological properties of semisolid pharmaceutical preparations may vary according to the applied temperature, temperatures of 25 and $37^{\circ} \mathrm{C}$ were selected for the viscosity measurements. The shear-dependent viscosity of the CS hydrogels and commercially available mucoadhesive gel Replens ${ }^{\mathrm{TM}}$ as a function of shear rate measured at 25 and $37^{\circ} \mathrm{C}$ is presented in Figure 3A,C.
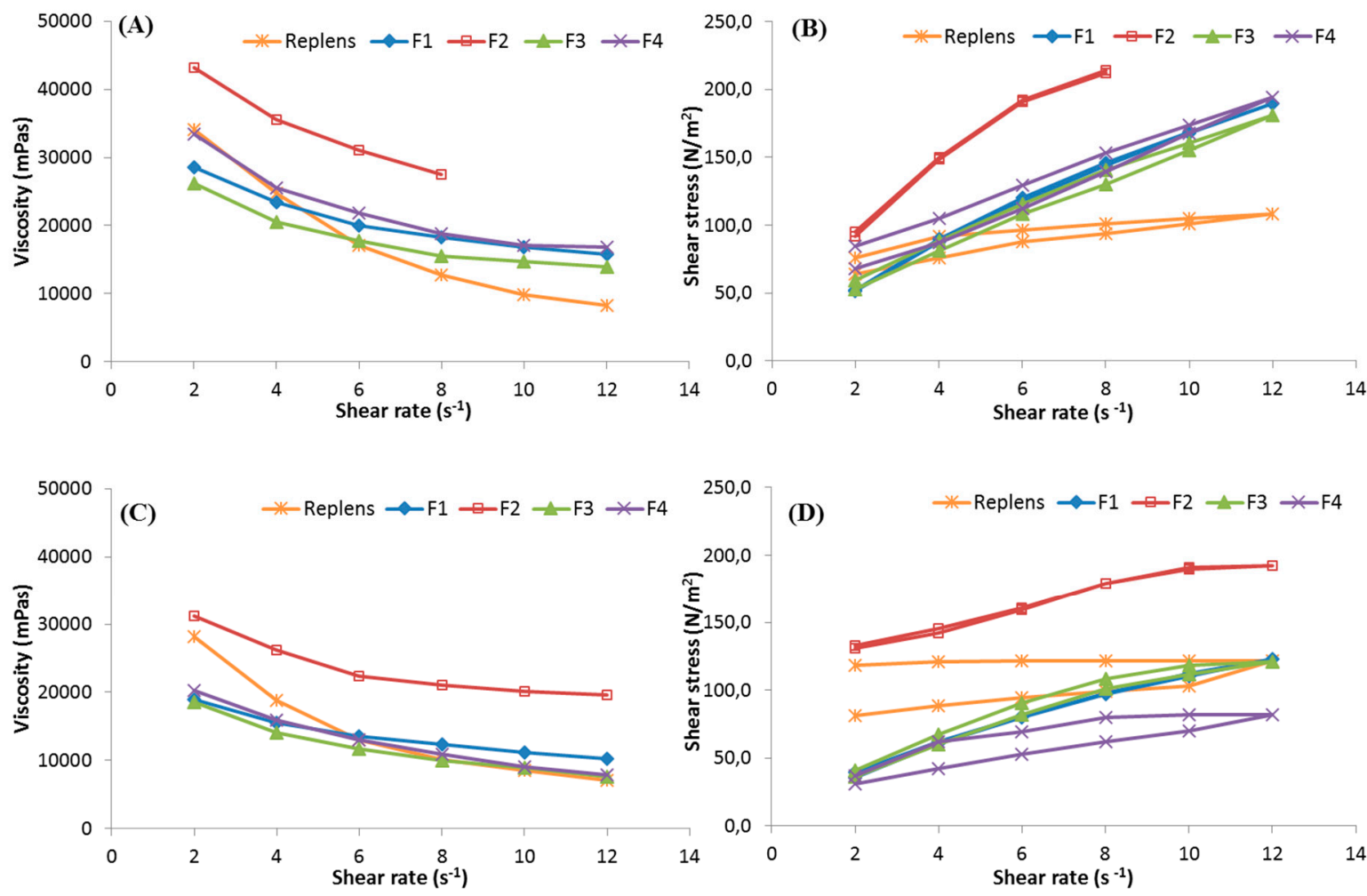

Figure 3. Influence of the shear rate on the rheological curves of unmodified CS (F1, F2), $\beta$-GP crosslinked CS hydrogels (F3, F4) and Replens ${ }^{\mathrm{TM}}$ measured at $25{ }^{\circ} \mathrm{C}$ (A) and $37{ }^{\circ} \mathrm{C}$ (C); The relationship between shear stress and shear rate of unmodified CS, CS / $\beta$-GP hydrogels and Replens ${ }^{\mathrm{TM}}$ (mean \pm S.D.; $n=3$ ) measured at $25^{\circ} \mathrm{C}(\mathbf{B})$ and $37^{\circ} \mathrm{C}(\mathbf{D})$.

It was found that ion crosslinked CS formulations F3 and F4 displayed lower viscosities compared with unmodified CS hydrogels (Table 3). A significant drop (almost 2-fold) in viscosity of hydrogel F4 (in comparison to F2) was probably affected by greater ionic strength resultant from addition of higher amount of $\beta$-GP [37]. The rheological behavior was found to be comparable between the samples investigated at room and body temperature. However, it should be noted that all hydrogels were characterized by remarkably lower viscosities at $37^{\circ} \mathrm{C}$ (Figure 3C) than those obtained at $25^{\circ} \mathrm{C}$ (Figure 3A). The observed loss in hydrogels' strength in body temperature might be beneficial and favor the spreadability after administration. In all rheograms, a decrease in hydrogels' viscosity with growing shear rate was observed indicating non-Newtonian pseudoplastic behavior of all analyzed hydrogels. It was also noticed that at higher values of shear rates, CS 
hydrogels possessed higher viscosity compared with Replens ${ }^{\mathrm{TM}}$ (Figure 3A). Pseudoplastic semisolid formulations are considered to be more suitable for vaginal administration because they offer increased flow which helps not only in extrusion from applicator, but also enables avoidance of leakage from the administration site [38]. As shown in Figure 3B,D, only formulations F3 and F4 possessed thixotropic properties as evidenced by characteristic shift of the lower curve to the left compared to the upper one-known as the hysteresis loop. The observed ability to gradually recover of $\beta$-GP crosslinked CS formulations after removing the shear stress might aid better spreadability after application [39]. The results of rheological assessment indicated that the presence of $\beta$-GP is necessary for improving thixotropic behavior of CS hydrogels.

In order to provide deeper insight into the internal structure of the formulations and characterize their vaginal applicability, the mechanical properties of hydrogels' F1-F4 were evaluated using a texture analyzer. The results of hardness, cohesiveness, and compressibility measurements are given in Table 3. Hardness describes the ability to remove the formulation from the container. Low value of hardness is related to the ease of product removal and application but on the contrary, may decrease the retention time at the administration site [40]. In addition, together with the compressibility factor, hardness reflects the applicability to the desired site [41]. In turn, cohesiveness is a substantial parameter to determine the gel's reconstruction ability after administration. The higher the cohesiveness, the better structural recovery is usually observed, and as a result product performance at the application site may be improved [42].

Table 3. Mechanical properties of prepared hydrogels with unmodified or $\beta$-GP crosslinked CS compared to Replens $^{\mathrm{TM}}($ mean $\pm \mathrm{SD} ; n=3)$.

\begin{tabular}{cccccc}
\hline Formulation & $\begin{array}{c}\text { Viscosity } \\
(\mathbf{m P a s}) *\end{array}$ & $\begin{array}{c}\text { Viscosity } \\
(\mathbf{m P a s})\end{array}$ & $\begin{array}{c}\text { Hardness } \\
(\mathbf{m N})\end{array}$ & $\begin{array}{c}\text { Cohesiveness } \\
(\mu \mathbf{J})\end{array}$ & $\begin{array}{c}\text { Compressibility } \\
(\mathbf{m N})\end{array}$ \\
\hline Replens $^{\mathrm{TM}}$ & $17,068 \pm 92$ & $13,047 \pm 87$ & $494.5 \pm 10.1$ & $38.6 \pm 0.9$ & $1,064 \pm 28$ \\
F1 & $19,987 \pm 101$ & $13,493 \pm 100$ & $588.6 \pm 17.4$ & $40.7 \pm 0.1$ & $1,195 \pm 13$ \\
F2 & $31,048 \pm 85$ & $23,876 \pm 91$ & $978.2 \pm 14.9$ & $67.7 \pm 0.9$ & $1,875 \pm 31$ \\
F3 & $17,809 \pm 78$ & $11,651 \pm 81$ & $562.6 \pm 13.5$ & $39.1 \pm 0.9$ & $1,096 \pm 19$ \\
F4 & $21,828 \pm 112$ & $13,013 \pm 105$ & $654.0 \pm 12.6$ & $42.2 \pm 2.8$ & $1,173 \pm 52$ \\
\hline \multicolumn{5}{c}{${ }^{*}$ Measured at shear rate of $6 \mathrm{~s}^{-1}$ at $25^{\circ} \mathrm{C}^{* *}$ Measured at shear rate of $6 \mathrm{~s}^{-1}$ at $37^{\circ} \mathrm{C}}$.
\end{tabular}

As it is presented in Table 3, the hardness, cohesiveness, and compressibility values of the hydrogels were significantly affected by the concentration of CS. An increase in the polymers' concentration gradually increased all the mechanical parameters up to $60 \%$ of CS hydrogel F2 (compared to F1). These differences in texture parameters values observed between formulations F3 and F4 were found to be less pronounced. The addition of $\beta$-GP influenced hydrogels' hardness, consistency, and cohesiveness remarkably. It was noticed that hydrogels F3 and F4 possessed lower values of mechanical properties compared with formulations F1 and F2. The hardness, cohesiveness, and compressibility of the hydrogels decreased with a drop in viscosity of the formulations. A decrease in mechanical properties may be associated with higher ionic strength resulted from introduction higher amount of $\beta$-GP ions in formulation F4. This observation is consistent with literature wherein the addition of ions was one of the crucial parameters responsible for loosening the CS hydrogels' structure and decreasing the viscosity [37,43].

Based on the results of the rheological and mechanical measurements, it might be assumed that thixotropic hydrogels' F3 and F4 (with lower values of hardness and cohesiveness) appeared to be more spreadable and more easily applicable to the vaginal mucosa compared with F1 and F2.

\subsection{Swelling Index and Mucoadhesion Studies}

Water uptake ability of chitosan hydrogels is highly feasible for assuring a prolonged drug release profile and initiating mucoadhesive interactions between the polymer and mucosal surface. 
However, extensive swelling could cause discomfort and influence vaginal fluid flow after vaginal application. Therefore, swelling index studies of prepared hydrogels were undertaken and reported as the swelling index versus time in Figure 4.

The swelling of CS hydrogels is a complex process which can be divided into several stages: diffusion of water molecules into the polymer network followed with the relaxation of hydrated chains and the expansion of the polymer network in the aqueous media [44]. The swelling behavior depends on the media $\mathrm{pH}$ and ionization of the polymer's functional groups, network structure, degree of crosslinking, and the nature of crosslinking agent [45]. The degree of CS and CS/ $\beta$-GP hydrogels swelling was found to be polymer concentration-dependent. All investigated hydrogels' curves displayed an initial rapid growth within $30 \mathrm{~min}$ due to the entry of the aqueous solution via metastable pores, which is known as hysteresis of swelling mechanism [46]. However, formulations with unmodified CS (F1 and F2) were found to swell more rapidly (reaching the highest value of SI 3.61 and 4.05 within first $45 \mathrm{~min}$ of the test, respectively) and started to dissolve within $60 \mathrm{~min}$ at $37^{\circ} \mathrm{C}$. This enhanced water uptake ability might be attributed to their high porosity as indicated by the SEM picture. In acidic solutions, a high degree of protonation of CS amino groups is responsible for electrostatic repulsion between charged chains resulting in expansion of the CS network and quick swelling. CS/ $\beta$-GP hydrogels displayed a slower degree of swelling compared with unmodified CS formulations, with formulation F4 attaining the lowest value of SI 1.79. In addition, ion crosslinked hydrogels were more stable during the study and a decrease in SI (attributed to slow hydrogels' dissolution) after $3-4 \mathrm{~h}$ of the test occurring. A decrease in CS/ $\beta$-GP swelling capacity could be attributed to creation of a more compact structure with a protective polyol layer, formed through interchain hydrogen bonds, around the CS chains. Thus, it may be concluded that CS network was freely penetrated by water, but relaxation of its chains in the presence of $\beta$-GP was limited. However, according to the literature [33], a decrease in polymer solubility resulting from hydrophobic interactions and intrachain electrostatic repulsion in the presence of $\beta$-GP could have taken place, which might be responsible for drop in swelling capacity as well. Slower extent of CS/ $\beta$-GP matrix dissolution in acidic media might also result from gelation the CS/ $\beta$-GP delivery systems (observed within $4 \mathrm{~h}$ of the study, Table 2) and formation of a more viscous swollen gel.

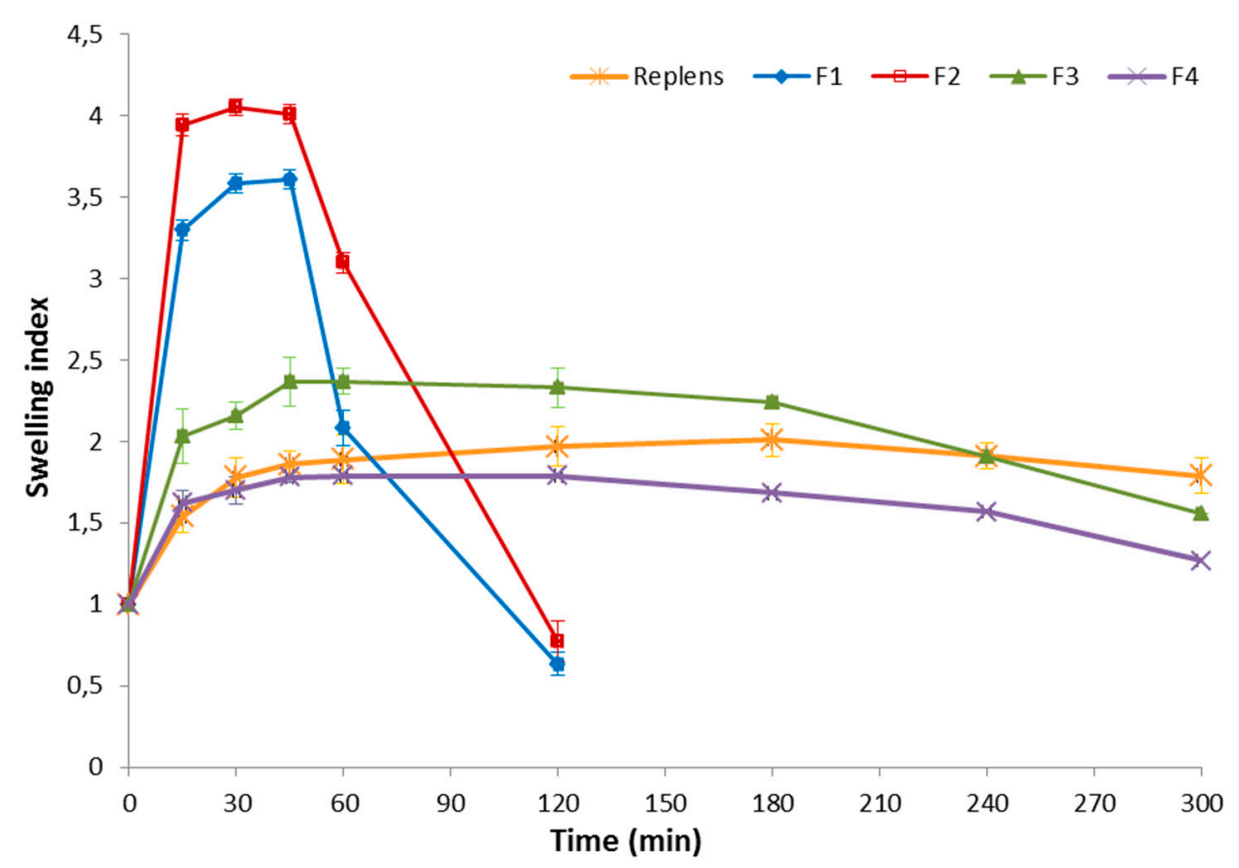

Figure 4. Swelling index study of CS formulations F1-F4 (mean \pm S.D.; $n=3$ ). 
In order to investigate hydrogel behavior in contact with mucosal surface, mucoadhesive studies were additionally performed. Mucoadhesion is defined as a type of interaction between material (e.g., usually polymer) with either secreted mucus or a mucosal membrane [47,48]. The mechanism of mucoadhesion involves a contact stage between the mucoadhesive and mucosal layer and a subsequently consolidation stage, that comprises several physicochemical interactions (including van der Waals and hydrogen bonds or electrostatic interactions) which strengthen the material-mucin connection, providing intimate and prolonged adhesion [49]. Porcine vaginal mucosa was used for the imitation of vaginal mucoadhesion due to the similarity of porcine and human vaginas in terms of anatomical structure, $\mathrm{pH}$, and vaginal secretion [50]. The effect of CS concentration and $\beta$-GP crosslinking on the force of detachment $\left(F_{\max }\right)$ and work required to overcome the hydrogel-porcine vaginal mucosa interaction $\left(W_{\mathrm{ad}}\right)$ is presented in Figure 5A,B. All examined hydrogels showed mucoadhesive properties, expressed as $F_{\max }$ with the range of 0.26 to $0.47 \mathrm{~N}$ and $W_{\text {ad }}$ between 311.6 and $435.5 \mu \mathrm{J}$. The hydrogels' ability to interact with porcine vaginal mucosa was found to be comparable to the values obtained with the reference mucoadhesive gel Replens ${ }^{\mathrm{TM}}$. As it is shown in Figure 5, the strength of the mucoadhesive connection increased with the concentration of unmodified CS in the formulations.
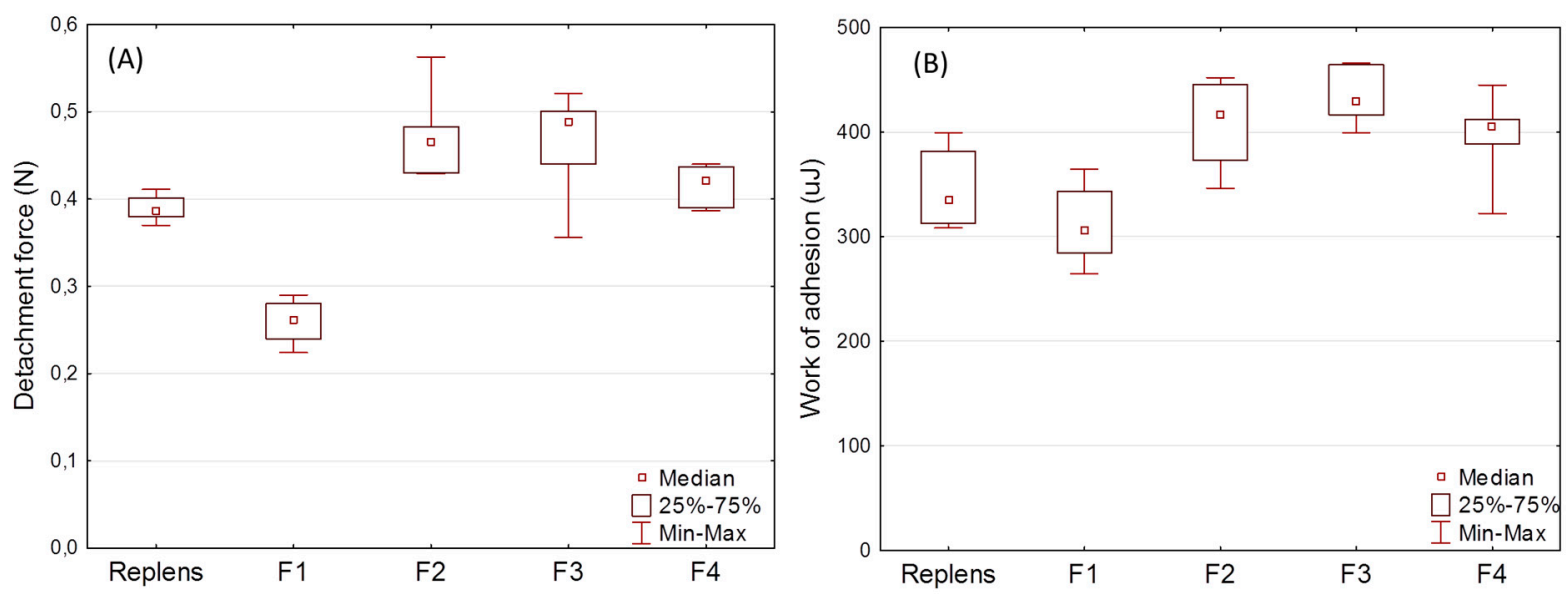

Figure 5. Box-plot graphs presenting mucoadhesive properties: (A) maximum force of detachment; (B) work of adhesion of formulations F1-F4 and mucoadhesive vaginal gel Replens ${ }^{\mathrm{TM}}$ (median; $n=6$ ).

The higher mucoadhesive properties of formulation F2 (compared with F1) resulted from the stronger cationic behavior and the presence of higher amount of free hydroxyl and amino groups enabling polymer to interact with mucin by hydrogen and electrostatic bonding. The obtained results were confirmed by swelling index studies (Figure 4), and showed a direct correlation between swelling behavior of hydrogel F1 and F2 and their ability to interact with porcine vaginal mucosa. However, it should be noted that enhanced mucoadhesion strength of F2 may also be related to its higher viscosity (Table 3).

Several studies revealed that the presence of crosslinker influenced CS mucoadhesiveness as a result of a drop in positively charged free amino groups, reducing the polymer chains' mobility and ability to interact with mucosal surface [9,51]. Surprisingly, CS/ $\beta$-GP hydrogels were noticed to possess comparable (F4 vs. F2) or even higher (F3 vs. F1) values of mucoadhesive properties. This phenomenon might be explained by water transfer between mucosa and CS/ $\beta$-GP hydrogels at the contact stage of mucoadhesion. $\beta$-GP with glycerol moieties has the ability to attract free water and create a protective $\beta$-GP layer around CS molecules $[35,36]$, which may have caused dehydration of the mucus layer [52]. The higher water diffusion into CS/ $\beta$-GP network and formation of more cohesive structure of mucus-CS/ $\beta$-GP gel might have resulted in strengthening the mucoadhesive links. Nevertheless, it should be noted that incomplete CS crosslinking with $\beta$-GP partially 
maintained protonation of polymers' functional groups which were still capable of physicochemical interactions with mucus [35]. As a consequence, CS chains remained flexible enough to link with mucin chains. In addition, more pronounced hydrophobic interactions with porcine vaginal mucosa in the presence of $\beta$-GP also cannot be excluded [18]. Given these points, the mechanism of CS/ $\beta$-GP mucoadhesiveness appeared to be more complex and multifactorial compared to unmodified CS involving both cohesiveness factor as well as physicochemical interactions.

\subsection{Stability Studies}

Despite the great potential of using CS in drug delivery systems, its poor stability is a substantial drawback and needs to be estimated during pharmaceutical drug delivery systems development. CS and $\mathrm{CS} / \beta$-GP hydrogels were examined by drug content, $\mathrm{pH}$, particle size, and viscosity evaluation. Due to the fact that CS is very sensitive to environmental conditions [53,54], formulations were stored in closed containers at $4 \pm 2{ }^{\circ} \mathrm{C}$ for 4 -week period. No significant changes in hydrogels' physical appearance, $\mathrm{pH}$, particle size, and CLO content were observed [34]. Nevertheless, almost $17 \%$ and $9 \%$ decrease in viscosity upon 4-week of storage was displayed in formulations F1 and F2, respectively (Figure 6), probably as a result of proceeding CS chain scission via hydrolysis in acidic environment $[55,56]$. On the contrary, no remarkable differences $(p>0.05)$ in rheological properties of CS/ $\beta$-GP over storage were noticed, suggesting that addition of $\beta$-GP to CS hydrogels may have a protective effect on CS viscosity. As it was expected, a decrease in viscosity of hydrogels F1 and F2 appeared upon storage influenced CLO release profile from the semisolid drug carriers. It was previously shown that designed CS hydrogels exhibited prolonged drug release rates, which were affected by the presence of $\beta$-GP (Figure 7A) [12]. As shown in Figure 7B, CLO was definitely released faster from stored formulations F1 and F2 compared to freshly prepared formulations. After $6 \mathrm{~h}$, the total amount of CLO released from hydrogels F1 and F2 before and upon 4-week storage was found to be $114.8 \pm 11.9 \mu \mathrm{g} \cdot \mathrm{cm}^{-2}, 117.6 \pm 9.4 \mu \mathrm{g} \cdot \mathrm{cm}^{-2}, 130.5 \pm 11.9 \mu \mathrm{g} \cdot \mathrm{cm}^{-2}$ and $146.1 \mu \mathrm{g} \cdot \mathrm{cm}^{-2}$, respectively. In comparison, upon 4-week storage, the amount of CLO released from CS/ $\beta$-GP hydrogels F3 and F4 (98.2 $\pm 8.5 \mu \mathrm{g} \cdot \mathrm{cm}^{-2}$ and $95.8 \pm 7.8 \mu \mathrm{g} \cdot \mathrm{cm}^{-2}$ within $6 \mathrm{~h}$ of studies) was comparable to those obtained with freshly prepared formulations $\left(96.8 \pm 9.4 \mu \mathrm{g} \cdot \mathrm{cm}^{-2}\right.$ and $91.7 \pm 5.9 \mu \mathrm{g} \cdot \mathrm{cm}^{-2}$ for F3 and F4, respectively.

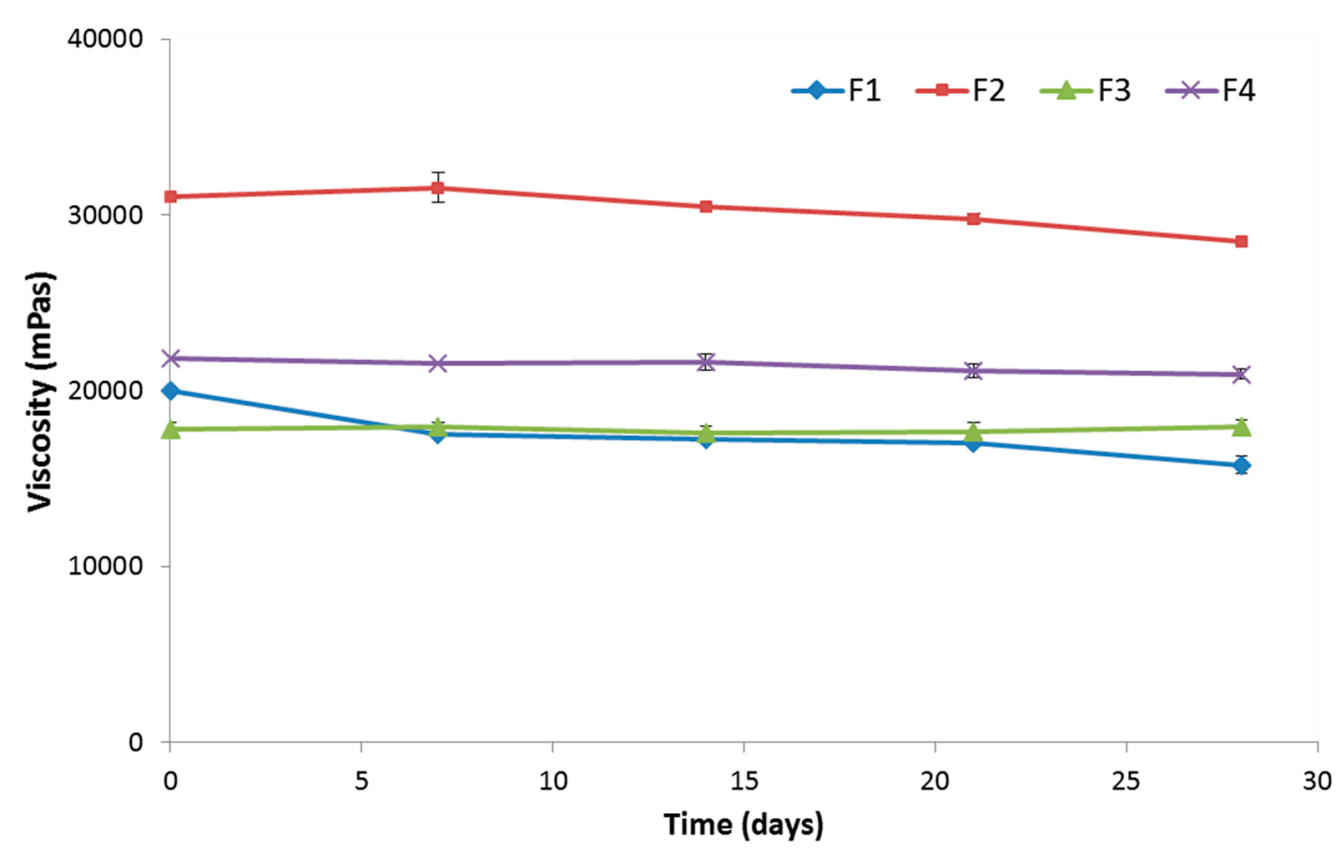

Figure 6. Viscosity of hydrogels F1-F4 in response to 4-week storage at $4{ }^{\circ} \mathrm{C}$ measured at shear rate $6 \mathrm{~s}^{-1}$ at $25^{\circ} \mathrm{C}($ mean \pm S.D.; $n=3)$. 


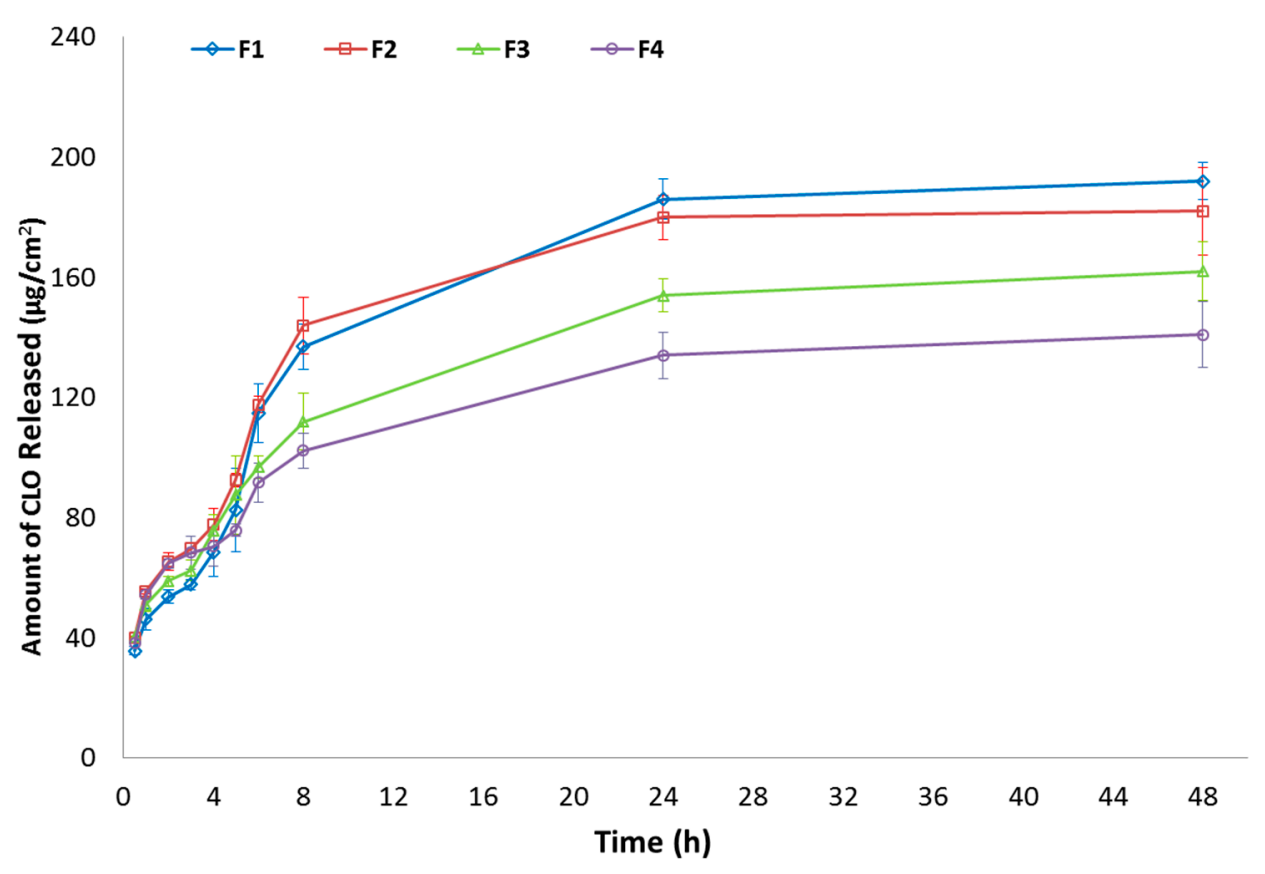

(A)

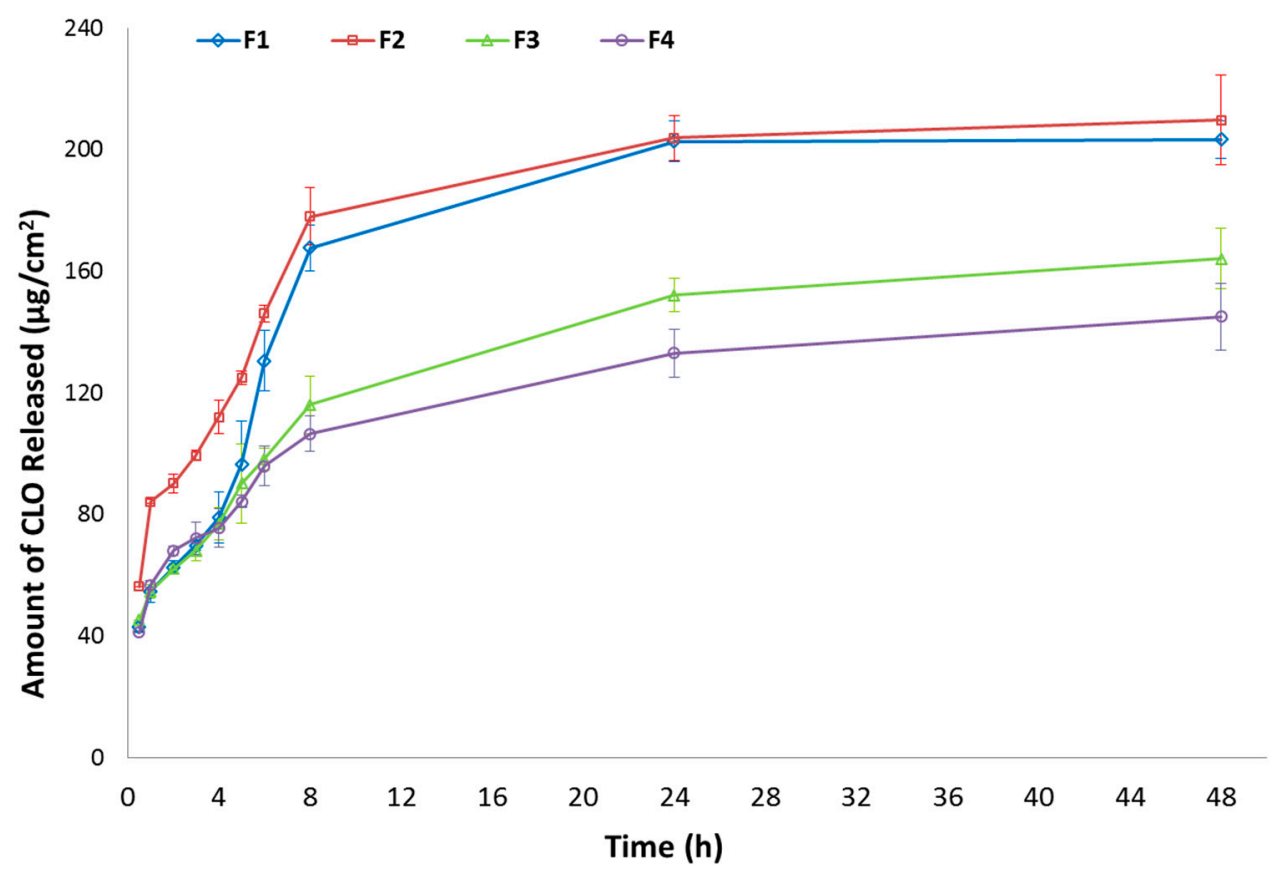

(B)

Figure 7. Amount of clotrimazole (CLO) per unit area $\left(\mu \mathrm{g} / \mathrm{cm}^{2}\right)$ released from different hydrogel formulations at $t=0$ (A) (according to [12]), and upon 4-week storage at $4{ }^{\circ} \mathrm{C}(\mathbf{B})($ mean \pm S.D.; $n=3)$.

\subsection{In Vitro Cytotoxicity Evaluation}

CS is thought to be a biocompatible and biodegradable material as it is biodegraded by a number of enzymes, such as lysozyme, di- $N$-acetylchitobiase, $N$-acetyl- $\beta$-D-glucosaminidase, and chitiotriosidase, which are present in human mucosa and other physiological fluids. Biodegradation of CS leads to the release of non-toxic oligosaccharides, which can be incorporated to glycosaminoglycans and glycoproteins or be excreted [56,57]. The non-toxicity and biocompatibility of CS was confirmed on several types of cells and after long-term oral administration [58]. As a 
result, CS has been widely used in biomedical applications (e.g., for the development of scaffolds for skin transplantation or wound dressings) and as diet supplement. Despite the fact that CS is widely used as a drug delivery carrier and has been extensively studied for topical $[59,60]$ and vaginal [61] drug delivery, its safety profile has still not been fully evaluated. The polymer biocompatibility can be influenced by the purity and the source of the material used, the particle size, degree of deacetylation, concentration, dosage form and the route of administration [58]. In addition, any modification of CS structure should be followed by an appropriate evaluation of its cytotoxicity, therefore the safety profile of unmodified CS and CS crosslinked with $\beta$-GP in human vaginal epithelial cells was evaluated in the present work. Two different concentrations of the ion crosslinker: low (lGP) - previously applied for CS hydrogels formulation, and high (hGP), which correspond with CS: $\beta$-GP weight ratio 1.0:0.63 and 1.0:4.0 respectively, were chosen for the investigations (Table 4). Necessary to obtain CS formulations with $\mathrm{pH} \approx 7.0$, hGP concentration was selected on the basis of extensive studies concerning thermoreversible CS/ $\beta$-GP systems undergoing sol-gel transition upon heating at $37^{\circ} \mathrm{C}[22,33,36]$. As molecular size of $\mathrm{CS}$ and $\mathrm{pH}$ of the medium are considered to be critical parameters responsible for perturbing effects on the cell membranes [62], thus the CS with low molecular weight $\mathrm{L}_{\mathrm{Mw}}(80-200 \mathrm{kDa})$ and medium molecular weight $\mathrm{M}_{\mathrm{Mw}}$ (200-400 kDa) were applied in the studies. To exclude the impact of formulation components and $\mathrm{pH}$ of the medium on the cell viability, several controls were employed concomitantly with experimental samples and summarized in Table 5.

Table 4. Different concentrations of $\beta$-GP crosslinked CS used for cytotoxicity studies.

\begin{tabular}{cccccc}
\hline Abbreviation & \multicolumn{5}{c}{$\mathbf{C S}\left(\mathbf{m g} \cdot \mathbf{~ m L}^{-\mathbf{1}}\right)+\beta-\mathbf{G P}\left(\mathbf{m g} \cdot \mathbf{~ m L}^{-\mathbf{1}}\right)$} \\
\hline CS/lGP & $0.01+0.006$ & $0.1+0.063$ & $0.5+0.315$ & $1.0+0.630$ & $3.0+1.890$ \\
CS/hGP & $0.01+0.04$ & $0.1+0.40$ & $0.5+2.00$ & $1.0+4.00$ & $3.0+12.00$ \\
\hline
\end{tabular}

Table 5. Abbreviations used in the in vitro cytotoxicity studies.

\begin{tabular}{|c|c|c|}
\hline Abbreviation & & Description \\
\hline K0 & & Non treated cells \\
\hline K1 & \multirow{8}{*}{ Cells treated with: } & Acetic buffer $\mathrm{pH} 4.0$ \\
\hline $\mathrm{K} 2$ & & Acetic buffer $\mathrm{pH} 4.5$ \\
\hline K3 & & Acetic buffer pH 7.0 \\
\hline K4 & & Aqueous solution of low $\beta$-GP * \\
\hline K5 & & Aqueous solution of high $\beta-G P *$ \\
\hline $0.01-3.0$ & & Concentrations of unmodified CS $\left(\mathrm{mg} \cdot \mathrm{mL}^{-1}\right)$ \\
\hline$(0.01-3.0)+1 G P$ & & CS crosslinked with low $\beta$-GP (CS: $\beta-$ GP 1.0:0.63) \\
\hline$(0.01-3.0)+$ hGP & & CS crosslinked with high $\beta$-GP (CS: $\beta$-GP 1.0:4.0) \\
\hline
\end{tabular}

* The amount of $\beta$-GP $45 \%(w / w)$ added corresponding with CS concentration (precise description is given in Table 4).

The MTT assay - a quantitative and rapid colorimetric method was chosen to preliminary screen the cytotoxicity range of CS, CS/lGP and CS/hGP. The MTT test is based on the cleavage of yellow tetrazolinum salt (MTT) to insoluble purple formazon crystals in the presence of mitochondrial dehydrogenase of viable cells. The results shown in Figure 8 summarize the viability of CRL 2616 cells treated for $4 \mathrm{~h}$ with CS and CS/ $\beta-G P$ as a function of $M w$ and concentration. 

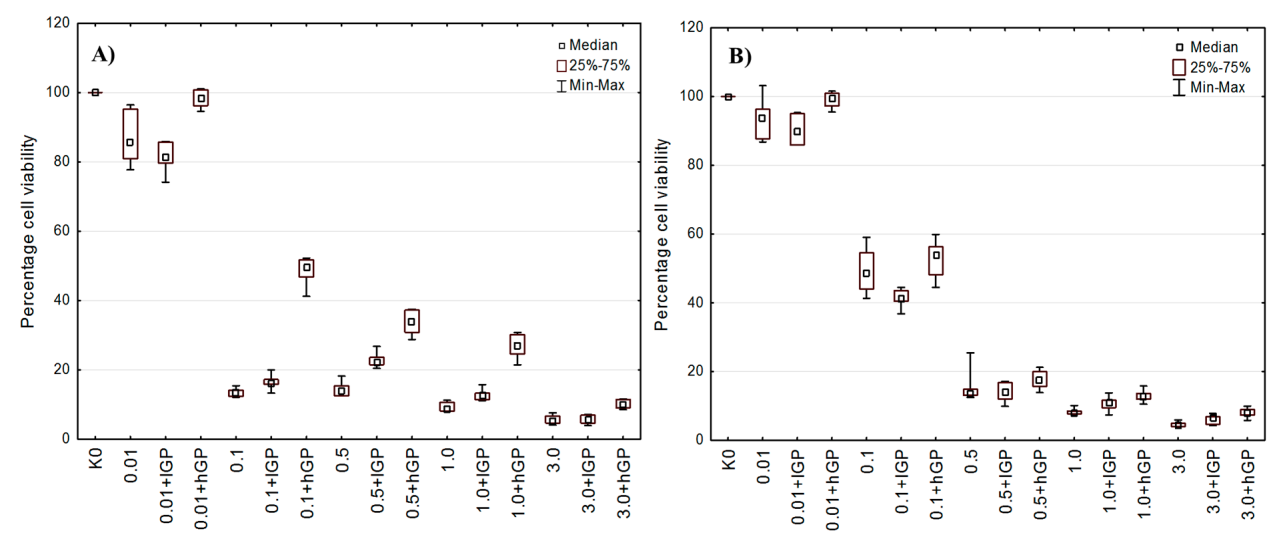

Figure 8. Box-plot graphs presenting the viability of CRL 2616 cells incubated for $4 \mathrm{~h}$ with different concentrations (expressed in $\mathrm{mg} \cdot \mathrm{mL}^{-1}$ ) of unmodified or $\beta$-GP crosslinked (A) $\mathrm{L}_{\mathrm{Mw}}$ or $(\mathbf{B}) \mathrm{M}_{\mathrm{Mw}}$ measured by using MTT assay (median; $n=6$ ).

Unmodified and ion crosslinked CS showed dose-dependent cytotoxicity in the concentration range of 0.01 to $3.0 \mathrm{mg} \cdot \mathrm{mL}^{-1}$. The lowest applied concentration of CS $0.01 \mathrm{mg} \cdot \mathrm{mL}^{-1}$ displayed low cytotoxicity (median of cell viability $82.1 \%-100.3 \%$ ), whereas a significant loss of viable cells (median $16.8 \%-56.7 \%)(p<0.05)$ at concentration $0.1 \mathrm{mg} \cdot \mathrm{mL}^{-1}$ was noticed. Samples with CS at concentration $1.0 \mathrm{mg} \cdot \mathrm{mL}^{-1}$ led to almost $90 \%$ cell death except for CS with $\mathrm{L}_{\mathrm{Mw}}$ crosslinked with hGP for which a lower cytotoxic response was noticed (median of cell viability $26.8 \%$ ). Interestingly, the MTT assay showed that mitochondrial functions varied markedly between cells exposed to unmodified CS and CS/ $\beta$-GP. Generally, CS/ $\beta$-GP exhibited lower inhibitory effect on CRL 2616 cells viability compared with unmodified CS. Furthermore, the higher amount of $\beta$-GP added to crosslink CS, the lower cytotoxicity was observed. The inhibition of the cell viability did not appear to be directly influenced by CS molecular weight. However, CS with $\mathrm{L}_{\mathrm{Mw}}$ crosslinked with hGP was found to exert lower cytotoxicity (the estimated rate of the cell viability was $50.6 \%, 33.9 \%$ and $26.8 \%$ for concentrations $0.1,0.5$ and $1.0 \mathrm{mg} \cdot \mathrm{mL}^{-1}$, respectively) (Figure $8 \mathrm{~B}$ ). In the present studies, unmodified CS being positively charged could interact with membrane phospholipids mainly through electrostatic interactions causing CRL 2616 cell membrane disruption [63].

The cellular cytotoxicity evoked by unmodified CS is not entirely unexpected as Prego et al., reported cytotoxic effect of CS nanoparticles on Caco-2 human epithelial colorectal adenocarcinoma cells at concentrations of $1.0 \mathrm{mg} \cdot \mathrm{mL}^{-1}$ [64]. Performed studies on CS powder also revealed cytotoxic effect of the polymer on normal human dermal fibroblasts in vitro in a dose-dependent manner [60]. In order to facilitate polymer biocompatibility, numerous studies have recently focused on the development of modified CS drug carriers. The in vitro cytotoxicity of the CS-protein scaffold crosslinked with genipin designed for wound healing confirmed no cytotoxicity in mouse fibroblasts [59]. Cytotoxicity studies conducted on glycol CS hydrogels with progesterone revealed no significant influence on the viability of human vaginal epithelial cells [15]. It has also been reported that tenofovir-loaded, thiolated and nonthiolated CS nanoparticles had no cytotoxic effect on vaginal epithelial cells [61]. In contrast, Depani et al., found that CS/glycerol phosphate gels exhibit dose-dependent cytotoxicity on mouse fibroblasts L-929 cells [29].

Lesser degrees of cytotoxicity observed in CRL 2616 incubated with $\beta$-GP crosslinked CS could be attributed to partial inactivation of CS protonated amino groups and consequently weakened molecular interaction between polycationic polymer and anionic cell surface. Nevertheless, Ahmadi et al., revealed that cytotoxicity of CS/ $\beta$-GP in goat bone marrow derived from mesenchymal stem cell increased with addition of higher concentration of crosslinking agent [65]. This is in contrast with our findings, where CS/hGP formulations were found to evoke less influence on CRL 2616 cell viability compared with CS/lGP. 
To explain the nature of cell death induced by CS and CS/ $\beta$-GP in human vaginal epithelial cells, two independent methods: flow cytometry and fluorescence microscopy assessment, were performed. Based on the preliminary results from the MTT assay, two CS concentrations: 0.1 and $1.0 \mathrm{mg} \cdot \mathrm{mL}^{-1}$ were applied in these studies referring to $17 \%-57 \%$ and $9 \%-27 \%$ CRL 2616 cells viability, respectively.

Flow cytometric analysis enables to detect the type of cell death after annexin V-FITC and propidium iodide staining. During the early phase of apoptosis, lipid phosphatidyloserine translocates from the internal to the external surface of the plasma membrane and becomes exposed at the cell surface, enabling recognition by macrophages [66]. Annexin V binds with high affinity to phosphatidylserine and can thus be evaluated to identify cells in all stages of programmed cell death $[67,68]$. In the later stage of apoptosis, membrane integrity is lost. Propidium iodide, red dye enters the cells with disrupted membrane and intercalates DNA, enhancing dye fluorescence proportionally to the number of damaged cells. It was noticed that unmodified CS exhibited a slightly higher degree of cytotoxicity compared with $\beta$-GP crosslinked CS (Figure 9B,C), which corresponds to the results from the MTT test.

The incubation of CRL 2616 cells with CS and CS/ $\beta$-GP at concentrations 0.1 and $1.0 \mathrm{mg} \cdot \mathrm{mL}^{-1}$ induced visible phosphatidylserine exposure after $4 \mathrm{~h}$ of incubation. At concentration of $1.0 \mathrm{mg} \cdot \mathrm{mL}^{-1}$, the percentage of apoptotic cells was increased from $6.40 \% \pm 0.63 \%$ to $24.90 \% \pm 2.22 \%$ for unmodified CS (with $\mathrm{M}_{\mathrm{Mw}}$ ), from $6.40 \% \pm 0.63 \%$ to $25.01 \% \pm 1.52 \%$ for CS/1GP and from $6.40 \% \pm 0.63 \%$ to $19.11 \% \pm 0.68 \%$ after incubation with CS/hGP. The apoptotic effect of CS and CS/1GP was stronger than that evoked by CS/hGP. Nevertheless, the percentage of necrotic cells was also increased after 4 $\mathrm{h}$ incubation (with CS concentration of $1.0 \mathrm{mg} \cdot \mathrm{mL}^{-1}$ ) and estimated $9.81 \pm 0.62 \%, 7.60 \pm 0.82 \%$ and $10.33 \% \pm 0.30 \%$ for CS, CS/1GP and CS/hGP, respectively compared to control $2.63 \pm 0.44 \%$. The differences in the nature of cell death evoked by CS with $\mathrm{L}_{\mathrm{Mw}}$ and $\mathrm{M}_{\mathrm{Mw}}$ were found to be statistically insignificant $(p>0.05)$.
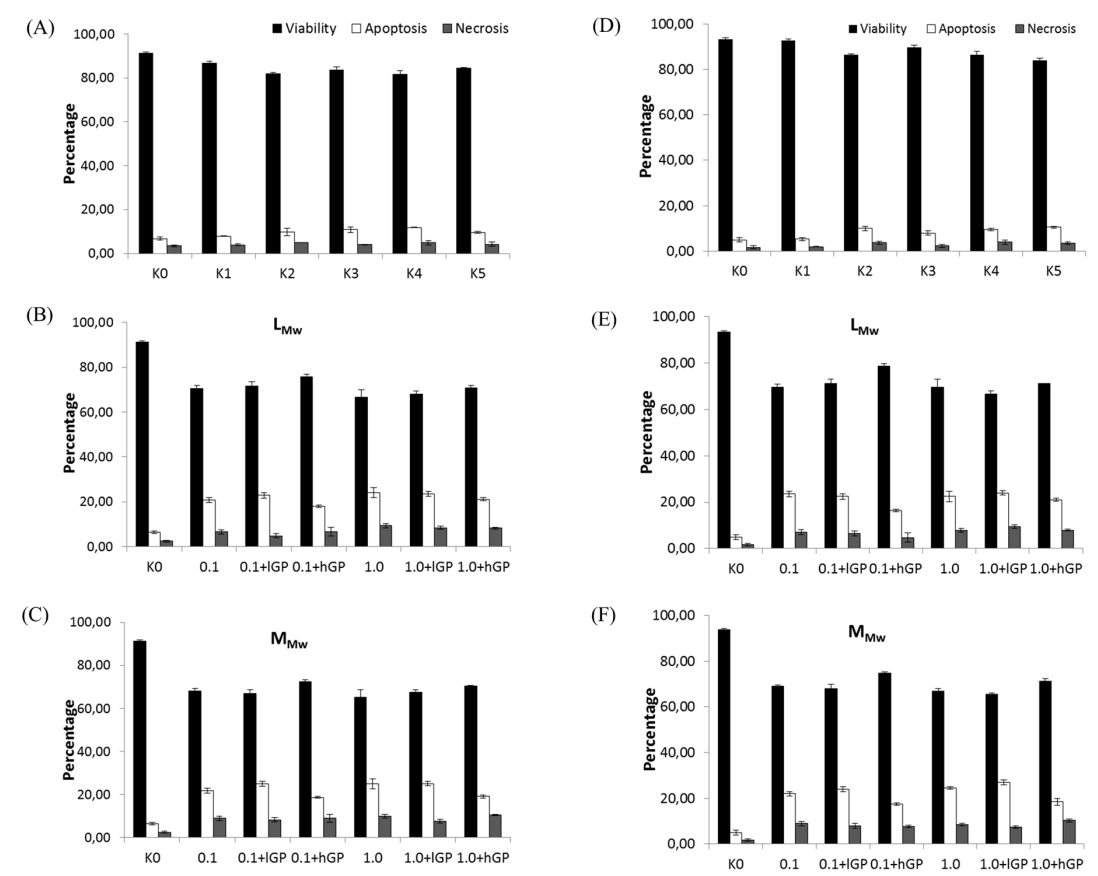

Figure 9. Results of the cytotoxicity studies (\% of cell viability, apoptosis and necrosis referred to non-treated cells) using flow cytometry (A-C) or fluorescent microscopy assay (D-F) after $4 \mathrm{~h}$ of exposure of human vaginal epithelial cells CRL 2616 with controls (as described in Table 5) (A,D), two concentrations $\left(0.1 ; 1.0 \mathrm{mg} \cdot \mathrm{mL}^{-1}\right)$ of unmodified or $\beta$-GP crosslinked $\mathrm{L}_{\mathrm{Mw}}(\mathrm{B}, \mathrm{E})$ or $\mathrm{M}_{\mathrm{Mw}} \mathrm{CS}$ $(\mathrm{C}, \mathrm{F})($ mean \pm S.D.; $n=3)$. 
CRL 2616 cells were also subjected to CS and CS/GP incubation followed by acridine orange/ethidium bromide double staining. Acridine orange (fluorescent DNA-binding dye) intercalates into DNA, making it appear green, and binds to RNA, staining it red/orange. Ethidium bromide is only taken up by nonviable cells. Its fluorescence overwhelms that of the acridine orange, making the chromatin of necrotic cells appear orange [69]. Mixture of both dyes is commonly used to observe characteristics of apoptosis: nuclear membrane disintegration and apoptotic body formation. Fluorescence microscopy images presented in Figure 10 clearly showed morphological changes after $4 \mathrm{~h}$ incubation with $1.0 \mathrm{mg} \cdot \mathrm{mL}^{-1} \mathrm{CS}$ with $\mathrm{M}_{\mathrm{Mw}}$ crosslinked with lGP.

Compared to spontaneous apoptosis observed in control cells (5.0\%), CRL 2616 cells treated with 0.1 or $1.0 \mathrm{mg} \cdot \mathrm{mL}^{-1} \mathrm{CS}$ showed increased percentages of early apoptotic cells (the highest rise displayed CS with $\mathrm{M}_{\mathrm{Mw}}$ crosslinked with lGP: $27.0 \% \pm 1.5 \%$ ) and increased percentage of necrotic cells (the highest rise displayed CS with $\mathrm{M}_{\mathrm{Mw}}$ crosslinked with hGP: 10.3\% $\pm 0.6 \%$ ) (Figure 9F). The results of fluorescence microscopy assessment demonstrated that the viability of CRL 2616 cells following exposures to unmodified and $\beta$-GP crosslinked CS samples (Figure 9D-F) was comparable to those obtained from the flow cytometry assay (Figure 9A-C). These results suggest that CS and CS/ $\beta$-GP predominantly induced CRL 2616 apoptosis, but also promoted their necrosis.

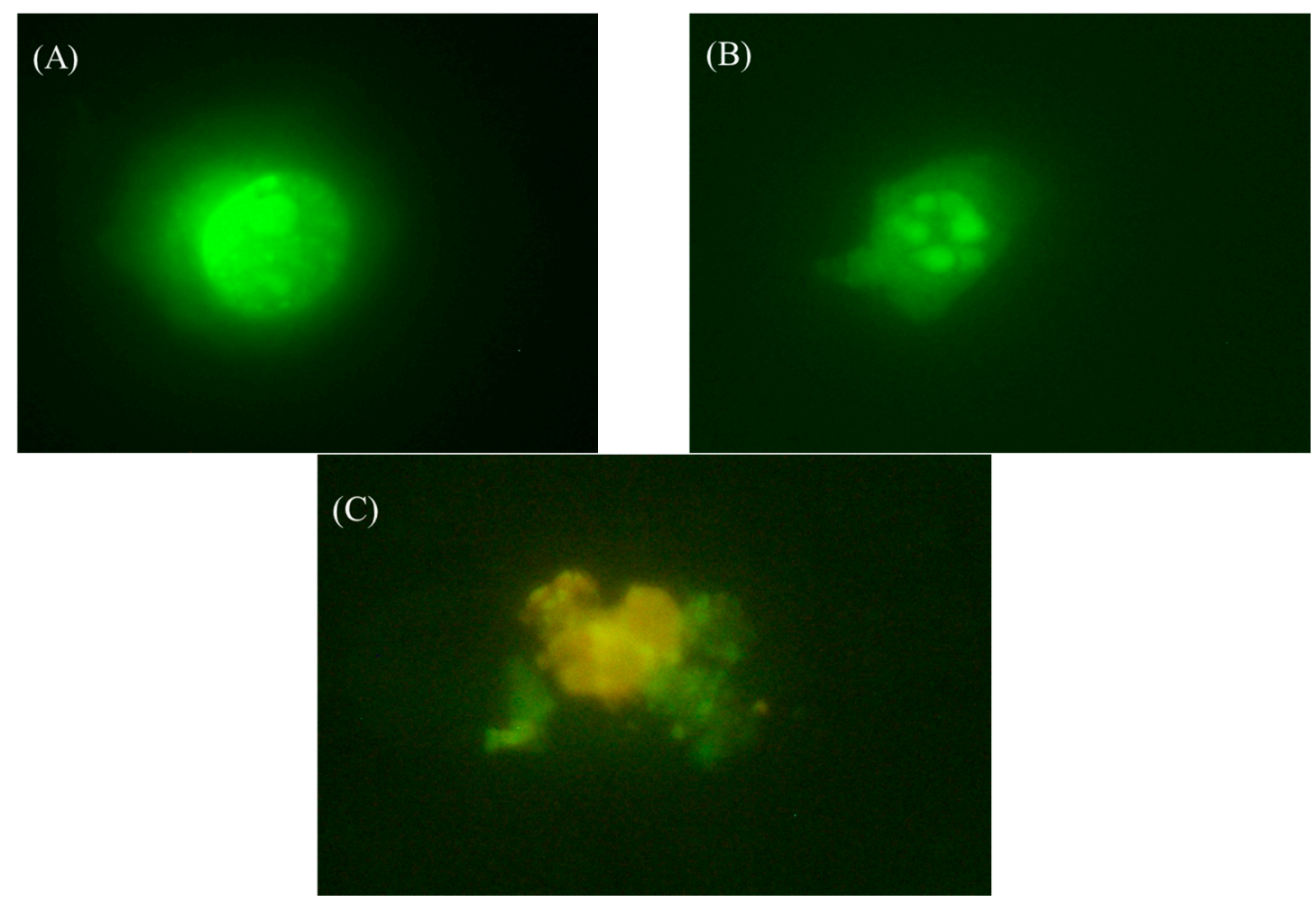

Figure 10. Representative fluorescence microscopy images of viable (A); apoptotic (B) and necrotic (C) human vaginal epithelial cell CRL 2616 incubated with CS/1GP at a concentration of $1.0 \mathrm{mg} \cdot \mathrm{mL}^{-1}$ after $4 \mathrm{~h}$ incubation (magnification $1000 \times$ ).

Interestingly, despite investigated concentrations of CS induced visible cytotoxic effects on CRL 2616 cells, the percentage of viability assessed by using flow cytometry and fluorescence microscopy analysis was considerably higher (over $65 \%-72 \%$ at concentration $1.0 \mathrm{mg} \cdot \mathrm{mL}^{-1}$ ) than those obtained using the MTT test (9\%-27\%). The differences in the quantification of the CRL 2616 cells' viability between applied methods might be attributed to different sensitivities of the assays used. In MTT test absorbance of control cells were considered as $100 \%$ and the percentages of viability were calculated as ratios to the non-treated cells. In the flow cytometry and fluorescence microscopy assay, the 
percentages of viable cells reflects the real numbers, being calculated as ratio to the total number of cells in treatment. In addition, the mitochondrial function assay (MTT) detected reduced metabolic activity rather than cell death itself [70], probably as a result of putting mechanical pressure on the underlying cells by increased osmolality and total concentration of CS formulations' components.

\section{Conclusions}

The results presented in this study indicate that $\beta$-GP modification of CS improved viscoelastic and mechanical performance of designed hydrogels with simultaneous maintaining of the polymers' favorable mucoadhesive properties. The water uptake ability of CS hydrogels was polymer concentration-dependent, and decreased significantly in the presence of $\beta$-GP crosslinker. Based on the results from the in vitro cytotoxicity studies, it can be assumed that CS displayed concentration-dependent cytotoxicity in the CRL 2616 cell line mainly through inducing apoptosis. $\beta$-GP crosslinked CS exhibited reduced cytotoxicity toward vaginal mucosa epithelial cells, as compared to unmodified CS, probably as a result of the steric effect of $\beta$-GP shielding polymers' positive charge, leading to less pronounced interaction with cell membranes components. However, further in vivo study is needed to provide more specific data concerning the influence of $\beta$-GP crosslinking on CS cellular toxicity.

Acknowledgments: This research was supported by Medical University of Białystok (number N/ST/ZB/15/002/2215). The equipment of Center BioNanoTechno: Leica EM AC 2000 (Wetzlar, Germany) and SEM Hitachi SH 200 (Tokyo, Japan) was partly supported by EU founds via project number POPW.O1.03.00-20-004/11.

Author Contributions: Emilia Szymańska and Katarzyna Winnicka conceived and designed the experiments, analyzed the data, wrote the paper. Emilia Szymańska accomplished preparation of hydrogels, mechanical and mucoadhesive studies and statistical analysis. Katarzyna Sosnowska evaluated viscosity measurements, Anna Basa performed SEM analysis and Wojciech Miltyk conducted the CRL 2616 cell culture. Małgorzata Rusak was responsible for fluorescence microscopy and flow cytometry analysis. All authors revised the manuscript and approved the final version.

Conflicts of Interest: The authors declare no conflict of interest.

\section{References}

1. Chien, Y.W. Drug delivery: Vaginal Route. In Encyclopedia of Pharmaceutical Technology, 3rd ed.; Swarbrick, J., Ed.; Informa Healthcare: New York, NY, USA, 2007; Volume 2, pp. 1339-1361.

2. Sandri, G.; Rossi, S.; Ferrari, S.; Bonferoni, M.C.; Caramella, C. Strategies to Improve Systemic and Local Availability of Drugs Administered via Vaginal Route. In Enhancement in Drug Delivery, 1st ed.; Touitou, B., Barry, B.W., Eds.; Taylor and Francis CRC Press: Boca Raton, FI, USA, 2007; pp. 441-470.

3. De Araújo Pereira, R.R.; Bruschi, M.L. Vaginal mucoadhesive drug delivery systems. Drug Dev. Ind. Pharm. 2012, 38, 643-652. [CrossRef] [PubMed]

4. Caramella, C.M.; Rossi, S.; Ferrari, F.; Bonferoni, M.C.; Sandri, G. Mucoadhesive and thermogelling systems for vaginal drug delivery. Adv. Drug Deliv. Rev. 2015, 92, 39-52. [CrossRef] [PubMed]

5. Franca, J.R.; Foureaux, G.; Fuscaldi, L.L.; Ribeiro, T.G.; Rodrigues, L.B.; Bravo, R.; Castilho, R.O.; Yoshida, M.I.; Cardoso, V.N.; Fernandes, S.O.; et al. Bimatoprost-loaded ocular inserts as sustained release drug delivery systems for glaucoma treatment: In vitro and in vivo evaluation. PLoS ONE 2014, 9, e95461. [CrossRef] [PubMed]

6. Kassem, M.A.; ElMeshad, A.N.; Fares, A.R. Lyophilized sustained release mucoadhesive chitosan sponges for buccal buspirone hydrochloride delivery: Formulation and in vitro evaluation. AAPS PharmSciTech 2014, 6, 1-11. [CrossRef] [PubMed]

7. Dehghan, M.H.G.; Kazi, M. Lyophilized chitosan/xanthan polyelectrolyte complex based mucoadhesive inserts for nasal delivery of promethazine hydrochloride. Iran. J. Pharm. Res. 2014, 13, 769-784.

8. Szymańska, E.; Winnicka, K.; Amelian, A.; Cwalina, U. Vaginal chitosan tablets with clotrimazole-design and evaluation of mucoadhesive properties using porcine vaginal mucosa, mucin and gelatin. Chem. Pharm. Bull. 2014, 62, 160-167. [CrossRef] 
9. Abruzzo, A.; Bigucci, F.; Cerchiara, T.; Saladini, B.; Gallucci, M.C.; Cruciani, F.; Vitali, B.; Luppi, B. Chitosan/alginate complexes for vaginal delivery of chlorhexidine digluconate. Carbohydr. Polym. 2013, 91, 651-658. [CrossRef]

10. Shaji, J.; Jain, V.; Lodha, S. Chitosan: A Novel Pharmaceutical Excipient. Int. J. Pharm. Appl. Sci. 2010, 1, 11-28.

11. Yeh, T.H.; Hsu, L.W.; Tseng, M.T.; Lee, P.L.; Sonjae, K.; Ho, Y.C.; Sung, H.W. Mechanism and consequence of chitosan-mediated reversible epithelial tight junction opening. Biomaterials 2011, 32, 6164-6173. [CrossRef] [PubMed]

12. Szymańska, E.; Winnicka, K.; Wieczorek, P.; Sacha, P.T.; Tryniszewska, E.A. Influence of unmodified and beta-glycerophosphate crosslinked chitosan on anti-Candida activity of clotrimazole in semi-solid delivery systems. Int. J. Mol. Sci. 2014, 15, 17765-17777. [CrossRef] [PubMed]

13. Kong, M.; Chen, X.G.; Xing, K.; Park, H.J. Antimicrobial properties of chitosan and mode of action: A state of the art review. Int. J. Food Microbiol. 2010, 144, 51-63. [CrossRef] [PubMed]

14. Palmeira-de-Oliveira, A.; Ribeiro, M.P.; Palmeira-de-Oliveira, R.; Gaspar, C.; Costa-de-Oliveira, S.; Correia, I.J.; Pina, V.; Martinez-de-Oliveira, J.; Queiroz, J.A.; Rodrigues, A.G. Anti-Candida activity of a chitosan hydrogel: Mechanism of action and cytotoxicity profile. Gynecol. Obstet. Investig. 2010, 70, 322-327. [CrossRef] [PubMed]

15. Almomen, A.; Cho, S.; Yang, C.H.; Li, Z.; Jarboe, E.A.; Peterson, C.M.; Huh, K.M.; Janát-Amsbury, M.M. Thermosensitive progesterone hydrogel: A safe and effective new formulation for vaginal application. Pharm. Res. 2015, 32, 2266-2279. [CrossRef] [PubMed]

16. Senyiğit, Z.A.; Karavana, S.Y.; Eraç, B.; Gürsel, O.; Limoncu, M.H.; Baloğlu, E. Evaluation of chitosan based vaginal bioadhesive gel formulations for antifungal drugs. Acta Pharm. 2014, 64, 139-156. [CrossRef] [PubMed]

17. Nilsen-Nygaard, J.; Strand, S.P.; Vårum, K.M.; Draget, K.I.; Nordgård, C.T. Chitosan: Gels and interfacial properties. Polymers 2015, 7, 552-579. [CrossRef]

18. Bernkop-Schnürch, A.; Hornof, M. Intravaginal drug delivery systems. Design, challenges, and solutions. Am. J. Drug Deliv. 2003, 1, 241-254. [CrossRef]

19. Bhattarai, N.; Gunn, J.; Zhang, M. Chitosan-based hydrogels for controlled, localized drug delivery. Adv. Drug Deliv. Rev. 2010, 62, 83-99. [CrossRef] [PubMed]

20. Aliaghaie, M.; Mirzadeh, H.; Dashtimoghadam, E.; Taranejoo, S. Investigation of gelation mechanism of an injectable hydrogel based on chitosan by rheological measurements for a drug delivery application. Soft Matter 2012, 8, 3128-3137. [CrossRef]

21. Ding, K.; Yang, Z.; Zhang, Y.L.; Xu, J.Z. Injectable thermosensitive chitosan/ $\beta$-glycerophosphate/collagen hydrogel maintains the plasticity of skeletal muscle satellite cells and supports their in vivo viability. Cell Biol. Int. 2013, 37, 977-987. [CrossRef] [PubMed]

22. Supper, S.; Anton, N.; Seidel, N.; Riemenschnitter, M.; Curdy, C.; Vandamme, T. Thermosensitive chitosan/glycerophosphate-based hydrogel and its derivatives in pharmaceutical and biomedical applications. Expert Opin. Drug Deliv. 2014, 11, 249-267. [CrossRef] [PubMed]

23. Niranjan, R.; Koushik, C.; Saravanan, S.; Moorthi, A.; Vairamani, M.; Selvamurugan, N. A novel injectable temperature-sensitive zinc doped chitosan/ $\beta$-glycerophosphate hydrogel for bone tissue engineering. Int. J. Biol. Macromol. 2013, 54, 24-29. [CrossRef] [PubMed]

24. Kauffman, C.A.; Carver, P.L. Use of azoles for systemic antifungal therapy. Adv. Pharmacol. 1997, 39, 143-189. [PubMed]

25. Czechowska-Biskup, R.; Jarosińska, D.; Rokita, B.; Ulański, P.; Rosiak, J.M. Determination degree of deacetylation of chitosan: Comparison of methods. Prog. Chem. Appl. Chitin Its Deriv. 2012, 17, 5-20.

26. Squier, C.A.; Mantz, M.J.; Schlievert, P.M.; Davis, C.C. Porcine vagina ex vivo as a model for studying permeability and pathogenesis in mucosa. J. Pharm. Sci. 2008, 97, 9-21. [CrossRef]

27. Rinaudo, M.; Pavlov, G.; Desbrières, J. Influence of acetic acid concentration on the solubilization of chitosan. Polymer 1999, 40, 7029-7032. [CrossRef]

28. EMA: Analytical Sieving General Chapter. Available online: http://www.ema.europa.eu/docs/en_GB/ document_library/Scientific_guideline/2010/01/WC500044305.pdf (accessed on 19 October 2015).

29. Depani, B.P.; Naik, A.A.; Nair, H.A. Preparation and evaluation of chitosan based thermoreversible gels for intraperitoneal delivery of 5-fluorouracil (5-FU). Acta Pharm. 2013, 63, 479-491. [CrossRef] 
30. Garg, T.; Chanana, A.; Joshi, R. Preparation of chitosan scaffolds for tissue engineering using freeze drying technology. IOSR J. Pharm. 2012, 2, 72-73. [CrossRef]

31. Wróblewska, M.; Winnicka, K. The effect of cationic polyamidoamine dendrimers on physicochemical characteristics of hydrogels with erythromycin. Int. J. Mol. Sci. 2015, 16, 20277-20289. [CrossRef] [PubMed]

32. Carmichael, J.; Degraff, W.; Gazdar, A.; Minna, J.; Mitchell, J. Evaluation of a tetrazolium-based semiautomated colorimetric assay: Assessment of chemosensitivity testing. Cancer Res. 1987, 47, 936-942.

33. Cho, J.; Heuzey, M.C.; Bégin, A.; Carreau, P.J. Physical gelation of chitosan in the presence of $\beta$-glycerophosphate: The effect of temperature. Biomacromolecules 2005, 6, 3267-3275. [CrossRef] [PubMed]

34. The United States Pharmacopeia, 29th ed.; the United States Pharmacopeial Convention: Rockville, MD, USA, 2011; Volume 2, pp. 1998-1999.

35. Chenite, A.; Buschmann, M.; Wang, D.; Chaput, C.; Kandani, N. Rheological characterisation of thermogelling chitosan/glycerol-phosphate solutions. Carbohydr. Polym. 2001, 46, 39-47. [CrossRef]

36. Ruel-Gariépy, E.; Chenite, A.; Chaput, C.; Guirguis, S.; Leroux, J. Characterization of thermosensitive chitosan gels for the sustained delivery of drugs. Int. J. Pharm. 2000, 203, 89-98. [CrossRef]

37. Chattopadhyay, D.P.; Inamdar, M.S. Aqueous behaviour of chitosan. Int. J. Polym. Sci. 2010, 2010, 1-7. [CrossRef]

38. Garg, S.; Anderson, R.A.; Chany, C.J., II; Waller, D.P.; Diao, X.H.; Vermani, K.; Zaneveld, L.J. Properties of a new acid-buffering bioadhesive vaginal formulation (ACIDFORM). Contraception 2001, 64, 67-75. [CrossRef]

39. Lee, C.H.; Moturi, V.; Lee, Y. Thixotropic property in pharmaceutical formulations. J. Control. Release 2009, 136, 88-98. [CrossRef]

40. Sezer, A.D.; Cevher, E.; Hatipoğlu, F.; Oğurtan, Z.; Baş, A.L.; Akbuğa, J. Preparation of fucoidan-chitosan hydrogel and its application as burn healing accelerator on rabbits. Biol. Pharm. Bull. 2008, 31, 2326-2333. [CrossRef] [PubMed]

41. Hurler, J.; Škalko-Basnet, N. Potentials of chitosan-based delivery systems in wound therapy: Bioadhesion study. J. Funct. Biomater. 2012, 3, 37-48. [CrossRef] [PubMed]

42. Hurler, J.; Engesland, A.; Kermany, B.P.; Škalko-Basnet, N. Improved texture analysis for hydrogel characterization: Gel cohesiveness, adhesiveness and hardness. J. Appl. Polym. Sci. 2012, 125, 180-188. [CrossRef]

43. Martínez-Ruvalcaba, A.; Chornet, E.; Rodrigue, D. Dynamic rheological properties of concentrated chitosan solutions. Appl. Rheol. 2004, 14, 140-147.

44. Zhang, X.Z.; Wu, D.Q.; Chu, C.C. Effect of the crosslinking level on the properties of temperature-sensitive poly(N-isopropylacrylamide) hydrogels. J. Polym. Sci. Polym. Phys. 2003, 41, 582-593. [CrossRef]

45. Berger, J.; Reist, M.; Mayer, J.M.; Felt, O.; Peppas, N.A.; Gurny, R. Structure and interactions in covalently and ionically crosslinked chitosan hydrogels for biomedical applications. Eur. J. Pharm. Biopharm. 2004, 57, 19-34. [CrossRef]

46. Wan, L.S.C.; Heng, P.W.S.; Won, L.F. Relationship between swelling and drug release in a hydrophilic matrix. Drug Dev. Ind. Pharm. 1993, 19, 1201-1210. [CrossRef]

47. Boddupalli, B.M.; Mohammed, Z.N.K.; Nath, R.A.; Banji, D. Mucoadhesive drug delivery system: An overview. J. Adv. Pharm. Technol. Res. 2010, 1, 381-387. [CrossRef] [PubMed]

48. Płaczek, M.; Sznitowska, M. The mucoadhesion phenomena and importance in drug application. Polim. Med. 2009, 39, 49-64. [PubMed]

49. Khutoryanskiy, V.V. Advances in mucoadhesion and mucoadhesive polymers. Macromol. Biosci. 2011, 11, 748-764. [CrossRef] [PubMed]

50. D'Cruz, O.J.; Erbeck, D.; Uckun, F.M. A study of the potential of the pig as a model for the vaginal irritancy of benzalkonium chloride in comparison to the nonirritant microbicide PHI-443 and the spermicide vanadocene dithiocarbamate. Toxicol. Pathol. 2005, 33, 465-476. [CrossRef] [PubMed]

51. Fernandes, M.; Gonçalves, I.C.; Nardecchia, S.; Amaral, I.F.; Barbosa, M.A.; Martins, M.C. Modulation of stability and mucoadhesive properties of chitosan microspheres for therapeutic gastric application. Int. J. Pharm. 2013, 454, 116-124. [CrossRef]

52. Mortazavi, S.A.; Smart, J.D. An investigation into the role of water movement and mucus gel dehydratation in mucoadhesion. J. Control. Release 1993, 25, 197-203. [CrossRef]

53. The European Pharmacopeia, 6th ed.; Council of Europe: Strasburg, France, 2007; Volume 2, pp. 1490-1491. 
54. Szymańska, E.; Winnicka, K. Stability of chitosan-a challenge for pharmaceutical and biomedical applications. Mar. Drugs 2015, 13, 1819-1846. [CrossRef] [PubMed]

55. Harding, S.E. Some observations on the effect of bioprocessing on biopolymer stability. J. Drug Target 2010, 18, 732-740. [CrossRef]

56. Kean, T.; Thanou, M. Biodegradation, biodistribution and toxicity of chitosan. Adv. Drug Deliv. Rev. 2010, 62,3-11. [CrossRef] [PubMed]

57. Dash, M.; Chiellini, F.; Ottenbrite, R.M.; Chiellini, E. Chitosan-A versatile semi-synthetic polymer in biomedical applications. Prog. Polym. Sci. 2011, 36, 981-1014. [CrossRef]

58. Baldrick, P. The safety of chitosan as a pharmaceutical excipient. Regul. Toxicol. Pharmacol. 2010, 56, $290-299$. [CrossRef] [PubMed]

59. Gorczyca, G.; Tylingo, R.; Szweda, P.; Augustin, E.; Sadowska, M.; Milewski, S. Preparation and characterization of genipin crosslinked porous chitosan collagen gelatin scaffolds using chitosan- $\mathrm{CO}_{2}$ solution. Carbohydr. Polym. 2014, 102, 901-911. [CrossRef] [PubMed]

60. Sabudin, S.; Derman1, M.A.; Zainol, I.; Noorsal, K. In vitro cytotoxicity and cell seeding studies of a chitosan-silver composite for potential wound management applications. J. Eng. Sci. 2012, 8, $29-37$.

61. Meng, J.; Zhang, T.; Agrahari, V.; Ezoulin, M.J.; Youan, B.B. Comparative biophysical properties of tenofovir-loaded, thiolated and nonthiolated chitosan nanoparticles intended for HIV prevention. Nanomedicine 2014, 9, 1595-1612. [CrossRef] [PubMed]

62. Rodrigues, S.; Dionísio, M.; Remuñán López, C.; Grenha, A. Biocompatibility of chitosan carriers with application in drug delivery. J. Funct. Biomater. 2012, 3, 615-641. [CrossRef]

63. Pavinatto, F.J.; Pavinatto, A.; Caseli, L.; dos Santos, D.S., Jr.; Nobre, T.M.; Zaniquelli, M.E.; de Oliveira, O.N., Jr. Interaction of chitosan with cell membrane models at the air-water interface. Biomacromolecules 2007, 8, 1633-1640. [CrossRef] [PubMed]

64. Prego, C.; Torres, D.; Alonso, M.J. Chitosan nanocapsules as carriers for oral peptide delivery: Effect of chitosan molecular weight and type of salt on the in vitro behaviour and in vivo effectiveness. J. Nanosci. Nanotechnol. 2006, 6, 2921-2928. [CrossRef] [PubMed]

65. Ahmadi, R.; de Bruijn, J.D. Biocompatibility and gelation of chitosan-glycerol phosphate hydrogels. J. Biomed. Mater. Res. A 2008, 86, 824-832. [CrossRef] [PubMed]

66. Martin, S.J.; Reutelingsperger, C.P.M.; McGahon, A.J.; Rader, J.A.; van Schie, R.C. Early redistribution of plasma membrane phosphatidylserine is a general feature of apoptosis regardless of the initiating stimulus: Inhibition by overexpression of Bcl-2 and Abl. J. Exp. Med. 1995, 182, 1545-1556. [CrossRef]

67. Winnicka, K.; Bielawski, K.; Bielawska, A. Synthesis and cytotoxic activity of G3 PAMAM-NH 2 dendrimer-modified digoxin and proscillaridin A conjugates in breast cancer cells. Pharmacol. Rep. 2010, 62, 414-423. [CrossRef]

68. Vermes, I.; Haanen, C.; Steffens-Nakken, H.; Reutelingsperger, C. A novel assay for apoptosis. Flow cytometric detection of phosphatidylserine expression on early apoptotic cells using fluorescein labelled annexin V. J. Immunol. Methods 1995, 184, 39-51. [CrossRef]

69. Martin, D.; Lenardo, C. Morphological, biochemical and flow cytometric assays of apoptosis. Curr. Protoc. Mol. Biol. 2001, 14,1-16.

70. Oh, H.; Livingston, R.; Smith, K.; Abrishamian-Garcia, L. Comparative study of the time dependency of cell death assays. MIT Undergrad. Res. J. 2004, 11, 53-62.

(C) 2015 by the authors; licensee MDPI, Basel, Switzerland. This article is an open access article distributed under the terms and conditions of the Creative Commons by Attribution (CC-BY) license (http://creativecommons.org/licenses/by/4.0/). 